\title{
La evolución de la economía y la política económica norteamericanas en 1984-1985*
}

\author{
I. LA EVOLUCIÓN REGIENTE DE LA EGONOMÍA Y LA \\ POLÍTICA ECONÓMICA EN ESTADOS UNIDOS
}

\section{Introducción}

Durante el primer semestre de 1984 la economía estadounidense experimentó un acelerado proceso de crecimiento económico, en un contexto de reducción del desempleo y baja inflación. El dinamismo de la actividad económica decreció sensiblemente, sin embargo, en el segundo semestre del año. Durante la primera mitad de 1985 , la actividad económica continuó expandiéndose con extrema lentitud, alcanzando resultados muy inferiores a las previsiones de la Administración. En todo este período se mantuvieron $y$, en algunos casos, profundizaron un número de importantes desequilibrios. En primer lugar, las tasas reales de interés se mantuvieron elevadas en comparación con los registros históricos. En segundo lugar, el déficit federal ha continuado una tendencia creciente sin perspectivas de reducción significativa en el futuro inmediato, si se persiste en la actual política fiscal. En tercer lugar, el sector externo experimentó un sensible deterioro, alcanzando desequilibrios comerciales y en cuenta corriente sin precedentes. Como contrapartida, el masivo ingreso de capitales del exterior reforzó la posición del dólar y convirtió a la economía de Estados Unidos, en deudora neta con respecto al resto del mundo.

No obstante, el optimismo fundado en la evolución pasada y las perspectivas futuras constituyeron la tónica dominante del período, debido a los efectos expansivos del rápido crecimiento económico de Estados Unidos sobre el resto de la economía internacional. En efecto, el acelerado incremento de las importaciones norteamericanas contribuyó a aligerar la presión sobre la balanza comercial de un buen número de países en desarrollo de elevado endeudamiento, re-

* Informe preparado para la Sacretaría Permanente del Sistema Económico Latinoamericano (SELA). 
duciendo las tensiones que caracterizaron la economía internacional en el período 1982-83.

En lo que sigue se presenta un análisis de las principales líneas de evolución de la economía y la política económica de Estados Unidos durante el período 1984-1985.

\section{El comportamiento de la demanda global, el mercado de trabajo y los precios.}

A fines de 1984 la economía norteamericana ingresó al tercer año de la recuperación más dinámica de postguerra, después de la expansión asociada al conflicto de Gorea de la década de los cincuenta (véase Cuadro 1). Durante 1984, el producto nacional bruto real creció a una tasa anual del 6.8 por ciento, aunque registró marcadas oscilaciones en su comportamiento trimestral (véase Guadro 2) y una clara tendencia a la desaceleración en la segunda mitad del año. Este debilitamiento de la expansión económica continuó, asimismo, durante el primer semestre de 1985.

Durante 1984 el consumo real creció a una tasa anual del 5.3 por ciento, concentrada básicamente en el componente de bienes durables. Tal como puede apreciarse en el Cuadro 3, la tasa de aumento del ingreso personal fue alta durante el primer semestre de 1984 y se redujo en la segunda parte del año. Este hecho, agregado a un ligero incremento en la tasa de ahorros, afectó adversamente el crecimiento del gasto de consumo en la segunda mitad del año.

La inversión privada fija se expandió notablemente durante 1984, particularmente estimulada por la inversión no residencial. Aun cuando la inversión residencial continuó creciendo durante 1984, su desaceleración con respecto a los registros del año 1983 fue bastante significativa. La contribución de la inversión privada bruta al crecimiento del producto ha sido, en el período 1983-1984, sustancialmente mayor a la registrada en promedio en anteriores movimientos cíclicos. Durante 1984, el dinamismo en el comportamiento de la inversión fija no-residencial se concentró, también, en la primera parte del año. Como consecuencia del rápido crecimiento de la inversión privada bruta fija, su participación en el producto nacional se elevó a niveles record en las últimas décadas. Lo mismo no ocurrió, sin embargo, con la inversión neta, debido a la mayor proporción de inversiones en activos de corto plazo dentro de la inversión total.

$\mathrm{El}$ gasto federal en bienes y servicios continuó contribuyendo a la expansión de la demanda global durante 1984, manteniéndose la tendencia a un crecimiento más rápido del gasto de defensa. La acumulación de inventarios, por su parte, siguió representando durante 1984, un estímulo positivo para el crecimiento de la demanda global, si bien desplegó un comportamiento errático e inestable a lo. largo del año. 
Cuadro 1

GREGIMIENTO DEL PNB REAL EN LOS PRIMEROS OCHO TRIMESTRES DE REGUPERAGIONES GIGLIGAS (\%)

\begin{tabular}{|c|c|c|c|}
\hline \multirow[b]{2}{*}{$\begin{array}{l}\text { Ultimo trimestre de la } \\
\text { recesión: }\end{array}$} & \multicolumn{3}{|c|}{ Promedio anual de crecimiento en: } \\
\hline & $\begin{array}{l}\text { Primeros } \\
\text { cuatro } \\
\text { trimestres }\end{array}$ & $\begin{array}{l}\text { Segundos } \\
\text { cuatro } \\
\text { trimestres }\end{array}$ & $\begin{array}{l}\text { Primeros } \\
\text { ocho } \\
\text { trimestres }\end{array}$ \\
\hline \multicolumn{4}{|l|}{ Recuperación actual: } \\
\hline $1982 \mathrm{IV}$ & 6,8 & 5,6 & 6,0 \\
\hline \multicolumn{4}{|l|}{$\begin{array}{l}\text { Recuperaciones anteriores } \\
\text { en la postguerra: }\end{array}$} \\
\hline $1949 \mathrm{IV}$ & 18,3 & 5,9 & 9,6 \\
\hline 1954 II & 7,4 & 2,6 & 5,0 \\
\hline $1958 \mathrm{Ir}$ & 8,4 & 1,7 & 5,0 \\
\hline 19611 & 7,0 & 8,8 & 5,1 \\
\hline $1970 \mathrm{IV}$ & 4,7 & 7,0 & 5,8 \\
\hline $1975 \mathrm{I}$ & 6,7 & 4,4 & 5,5 \\
\hline $1980 \mathrm{IIX}$ & 4,0 & $-3,0$ & 0,4 \\
\hline $\begin{array}{l}\text { Promedio de cinco } \\
\text { recuperaciones* }\end{array}$ & 6,8 & 3,8 & 5,3 \\
\hline $\begin{array}{l}\text { Promedio de siete } \\
\text { recuperaciones }\end{array}$ & 7,4 & 3,1 & 5,2 \\
\hline
\end{tabular}

* Excluye las recuperaciones que se iniciaron en 1949 y 1980.

Fuente: Consejo de Asesores Económicos, Economic Report of the President. UsGPo. Washington D. C., febrero de 1985.

Por último, el balance externo continuó ejerciendo una influencia negativa sobre la demanda global. Durante 1984 el deterioro en las exportaciones netas fue bastante mayor que en el año anterior. Sin embargo, a diferencia de lo ocurrido durante 1983, a lo largo del último año las exportaciones de bienes y servicios se recuperaron, si bien a un ritmo notablemente inferior al de la expansión de las importaciones. Mientras que las exportaciones de bienes y servicios han tenido un comportamiento comparable al de la experiencia pasada, las importaciones han crecido significativamente más rápido que en recuperaciones previas. 


\section{Cuadro 2}

EVOLUGION DE LA DEMANDA GLOBAL

(Mil millones de dólares en 1972)

\begin{tabular}{|c|c|c|c|c|c|c|c|c|c|c|c|c|c|c|}
\hline & \multirow{2}{*}{$\frac{1981}{\text { Año }}$} & \multirow{2}{*}{$\frac{1982}{\text { Año }}$} & \multicolumn{5}{|c|}{1983} & \multicolumn{5}{|c|}{1984} & \multicolumn{2}{|c|}{1985} \\
\hline & & & Año & $\mathrm{I}$ & II & III & IV & Año & $\mathrm{I}$ & II & IIII & IV & $\mathrm{I}$ & IX \\
\hline $\begin{array}{l}\text { Gastos de consumo } \\
\text { Durables } \\
\text { No durables } \\
\text { Servicios }\end{array}$ & $\begin{array}{l}950,5 \\
140,9 \\
360,8 \\
448,8\end{array}$ & $\begin{array}{l}963,3 \\
140,5 \\
363,1 \\
459,8\end{array}$ & $\begin{array}{r}1.009,2 \\
157,5 \\
376,3 \\
475,4\end{array}$ & $\begin{array}{l}982,5 \\
146,8 \\
368,8 \\
466,8\end{array}$ & $\begin{array}{r}1.006,2 \\
156,2 \\
374,9 \\
475,1\end{array}$ & $\begin{array}{r}1.015,6 \\
159,6 \\
378,5 \\
477,6\end{array}$ & $\begin{array}{r}1.032,4 \\
167,2 \\
383,2 \\
482,0\end{array}$ & $\begin{array}{r}1.062,4 \\
178,1 \\
393,5 \\
490,8\end{array}$ & $\begin{array}{r}1.044,1 \\
173,7 \\
387,1 \\
483,4\end{array}$ & $\begin{array}{r}1.064,2 \\
178,6 \\
396,6 \\
488,9\end{array}$ & $\begin{array}{r}1.065,9 \\
177,0 \\
395,5 \\
493,5\end{array}$ & $\begin{array}{l}1.075,4 \\
182,9 \\
395,0 \\
497,5\end{array}$ & $\begin{array}{r}1.089,1 \\
187,0 \\
398,6 \\
503,5\end{array}$ & ** \\
\hline $\begin{array}{l}\text { Inversión privada fija } \\
\text { Residencial } \\
\text { No residencial }\end{array}$ & $\begin{array}{r}219,6 \\
44,5 \\
175,0\end{array}$ & $\begin{array}{r}204,7 \\
37,9 \\
166,9\end{array}$ & $\begin{array}{r}224,6 \\
53,7 \\
171,0\end{array}$ & $\begin{array}{r}207,8 \\
46,2 \\
161,6\end{array}$ & $\begin{array}{r}218,7 \\
53,4 \\
165,3\end{array}$ & $\begin{array}{r}229,8 \\
57,2 \\
172,6\end{array}$ & $\begin{array}{r}242,2 \\
57,8 \\
184,5\end{array}$ & $\begin{array}{r}265,1 \\
60,3 \\
205,2\end{array}$ & $\begin{array}{r}253,9 \\
60,6 \\
193,3\end{array}$ & $\begin{array}{r}263,7 \\
60,8 \\
202,9\end{array}$ & $\begin{array}{r}269,6 \\
60,1 \\
209,5\end{array}$ & $\begin{array}{c}273,1 \\
59,8^{*} \\
215,1\end{array}$ & $\begin{array}{c}273,0 \\
* * \\
*\end{array}$ & $\begin{array}{l}* * \\
* * \\
* *\end{array}$ \\
\hline $\begin{array}{l}\text { Gasto del Gobierno en } \\
\text { bienes y servicios } \\
\text { Federal } \\
\text { Defensa } \\
\text { No defensa } \\
\text { Estatal y local }\end{array}$ & $\begin{array}{r}287,0 \\
110,3 \\
73,5 \\
36,7 \\
176,8\end{array}$ & $\begin{array}{r}292,7 \\
117,0 \\
79,1 \\
37,9 \\
175,7\end{array}$ & $\begin{array}{r}291,9 \\
116,2 \\
84,7 \\
31,5 \\
175,7\end{array}$ & $\begin{array}{r}294,3 \\
119,0 \\
83,3 \\
35,7 \\
175,3\end{array}$ & $\begin{array}{r}292,4 \\
117,2 \\
84,8 \\
32,3 \\
175,2\end{array}$ & $\begin{array}{r}292,0 \\
115,6 \\
84,4 \\
31,2 \\
176,4\end{array}$ & $\begin{array}{r}288,0 \\
113,0 \\
86,3 \\
26,7 \\
175 ; 8\end{array}$ & $\begin{array}{r}302,1 \\
122,5 \\
89,4 \\
33,0 \\
179,6\end{array}$ & $\begin{array}{r}289,5 \\
112,2 \\
87,1 \\
25,2 \\
177,8\end{array}$ & $\begin{array}{r}302,1 \\
123,2 \\
89,6 \\
33,6 \\
178,9\end{array}$ & $\begin{array}{r}306,1 \\
125,0 \\
89,1 \\
36,0 \\
181,1\end{array}$ & $\begin{array}{c}310,5 \\
129,6 \\
92,1^{*} \\
37,0^{*} \\
180,9\end{array}$ & $\begin{array}{c}310,7 \\
129,8 \\
* * \\
* * \\
180,9\end{array}$ & $\begin{array}{l}* * \\
* * \\
* * \\
* * \\
* *\end{array}$ \\
\hline Demancia interna final & $1.457,1$ & $1.460,7$ & $1.525,7$ & $1.484,6$ & $1.517,3$ & $1.587,4$ & $1.562 ; 6$ & $1.629,6$ & $1.587,5$ & $1.630,0$ & $1.641,6$ & $1.659,0$ & $1.672,8$ & * \\
\hline Variación de inventarios & 11,3 & $-10,4$ & $-3,6$ & $-16,5$ & $-6,1$ & 0,9 & $7 ; 2$ & 24,8 & 31,6 & 20,8 & 30,6 & 16,8 & 19,1 & $* *$ \\
\hline Demanda interna total & $1.468,4$ & $1.450,3$ & $1.522,1$ & $1.468,1$ & $1.511,2$ & $1.538,3$ & $1.569,8$ & $1.654,4$ & $1.619,1$ & $1.650,3$ & $1.672,2$ & $1.675,8$ & $1.691,9$ & ** \\
\hline Balance externo* & 43,8 & 29,7 & 12,6 & 22,9 & 13,6 & 11,9 & 2,0 & $-15,0$ & $-8,3$ & $-11,4$ & $-27,0$ & $-13,4$ & $-28,4$ & $* *$ \\
\hline $\begin{array}{l}\text { Exportaciones de } \\
\text { bienes y servicios }\end{array}$ & 160,2 & 147,6 & 139,5 & 138,2 & 187,0 & 141,6 & 141,0 & 144,9 & 146,0 & 144,7 & 147,4 & 147,1 & 143,7 & $* *$ \\
\hline $\begin{array}{l}\text { Importaciones de } \\
\text { bienes y servicios }\end{array}$ & 116,4 & 118,0 & 126,9 & 115,3 & 123,4 & 129,7 & 139,1 & 161,1 & 153,2 & 156,2 & 174,4 & 160,5 & 172,1 & *** \\
\hline Producto nacional bruto & $1.512,2$ & $1.480,0$ & $1.534,7$ & $1.491,0$ & $1.524,8$ & $1.550,2$ & $1.572,7$ & $1.639,8$ & $1.610,9$ & $1.638,8$ & $1.645,2$ & $1.662,4$ & 1.663 .5 & $1.670,5$ \\
\hline $\begin{array}{l}\text { Producto (tasa anual de } \\
\text { crecimiento porcentaje) }\end{array}$ & 2,5 & $-2,1$ & 3,7 & 3,3 & 9,4 & 6,8 & 5,9 & 6,8 & 10,1 & 7,1 & 1,6 & 4,8 & 0,3 & 1,7 \\
\hline
\end{tabular}

* Cifras no revisadas.

* No dispenible.

FUENTE: Department of Commerce, Bureau of Economic Analysis. 
Cuadro 3

INGRESO PERSONAL, INGRESO DISPONIBLE Y TASA DE AHORROS

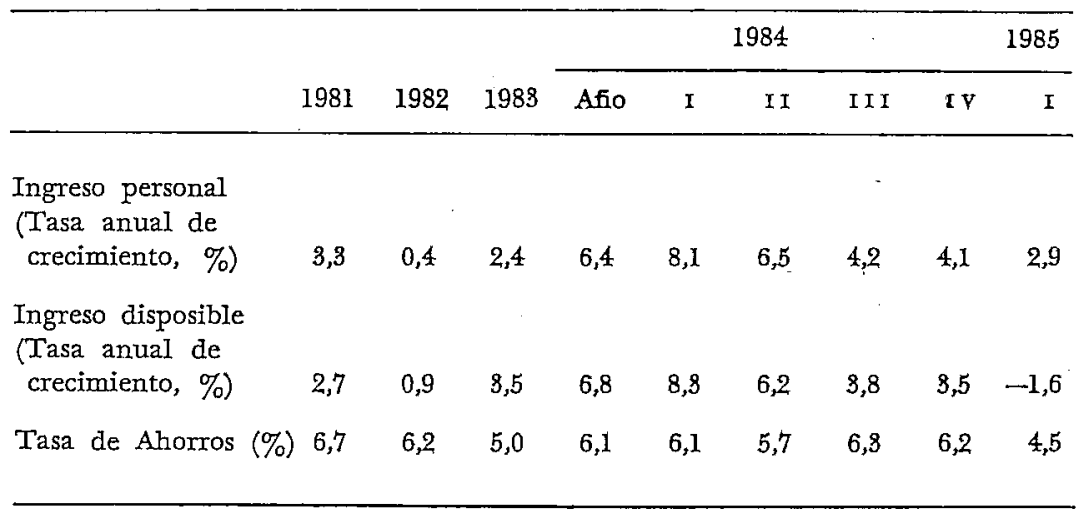

FUENTE: Department of Commerce, Bureau of Economic Analysis.

Por su parte, el mercado de trabajo siguió de cerca la evolución de la actividad económica general. Durante la primera mitad de 1984, el número de nuevos puestos de trabajo creció a una tasa anual del 4.7 por ciento, contra apenas 1.8 por ciento en el segundo semestre. Como puede verse en el Cuadro 4, mientras que entre el último trimestre de 1983 y mediados de 1984 la tasa de desempleo se redujo en un punto, durante el segundo semestre del último año apenas se contrajo en 0.3 puntos. Durante el primer cuarto de 1985, en cambio, la tasa de desocupación experimentó un ligero ascenso. Como consecuencia del mayor nivel de producción, la utilización de la capacidad instalada se incrementó hasta el tercer trimestre de 1984, si bien no llegó a alcanzar los registros del quinquenio 1976 1980. A partir del último cuarto de 1984, la utilización de la capacidad instalada se ha contraido regularmente.

A pesar del rápido crecimiento de la ocupación, el ritmo de aumento de los salarios nominales continuó siendo relativamente lento. Tal como puede apreciarse en el Caudro 5 , la tasa de aumento de los ingresos promedio por hora siguió desacelerándose en términos nominales durante 1984, aumentando durante el año a un ritmo de 3.3 por ciento, la tasa más baja desde 1964. El ligero incremento de la inflación durante 1984 resultó en una contracción de 
los ingresos reales por hora, la primera después de dos años consecutivos de crecimiento.

El comportamiento de la compensación real por hora en la presente recuperación ha divergido considerablemente de la experiencia de otros movimientos ć́clicos. Dado el dinámico crecimiento económico durante 1984, la contracción de 0.2 por ciento en la compensación real por hora es particularmente atípica. La desaceleración en el crecimiento de la compensación por hora y el mayor aumento de la productividad alentaron una disminución en los ritmos de aumento de los costos unitarios de la mano de obra. Este hecho -conjuntamente con el bajo precio relativo de la energía y el mantenimiento de un alto valor relativo del dólar- ha contribuido significativamente, por el lado de los costos, a mantener bajos los registros de aumento de precios.

\section{El sector externo}

Durante 1984 las cuentas externas norteamericanas continuaron experimentando un sensible deterioro. La balanza comercial duplicó el saldo deficitario de 1983 y alcanzó la cifra record de us\$123 mil millones. La mayor parte de este deterioro fue resultado del acelerado crecimiento de las importaciones, que aumentaron en valor a una tasa anual próxima al 27 por ciento. Las importaciones de productos manufacturados se expandieron, a su vez, a una tasa anual del 36 por ciento. Las exportaciones norteamericanas, por su parté, consiguieron crecer en apenas un 9 por ciento anual (véase Cuadro 6).

En el Guadro 7 puede apreciarse que el deterioro en la posición comercial externa de Estados Unidos alcanzó a la totalidad de los renglones, con la excepción del petróleo. Aún en las áreas de alta tecnologfa, bienes de capital y alimentos, la economía norteamericana ha pasado durante los últimos años a una situación de déficit o ha reducido sensiblemente su saldo positivo.

La balanza en cuenta corriente se deterioró de manera aún más notable durante 1984, como consecuencia de un saldo de servicios menos favorable. En efecto, en 1984 el déficit en cuenta corriente creció dos veces y media con relación a 1983, y alcanzó a us\$101 mil millones.

Naturalmente, este desequilibrio en cuenta corriente fue financiado por medio de movimientos de capital. Como puede verse en el Cuadro 8, durante 1984 aproximadamente un 47 por ciento del deterioro en la cuenta corriente fue financiado mediante una reducción en la salida de capital estadounidense hacia el exterior. El resto provino del incremento en la inversión extranjera en Estados Unidos. Por lo que respecta a la inversión estadounidense en el ex- 


\section{Cuadro 4}

MERGADO DE TRABAJO Y UTILIZACION

DE LA GAPACIDAD INSTALADA

\begin{tabular}{|c|c|c|c|c|}
\hline & $\begin{array}{c}\text { Total de } \\
\text { ocupados } \\
\text { (miles) }\end{array}$ & $\begin{array}{c}\text { Total de } \\
\text { desocupados } \\
\text { (miles) }\end{array}$ & $\begin{array}{c}\text { Tasa de } \\
\text { desempleo } \\
\%\end{array}$ & $\begin{array}{l}\text { Utilización de } \\
\text { la capacidad } \\
\text { instalada (\%) }\end{array}$ \\
\hline $1976 / 1980$ & - & - & 6,7 & 82,8 \\
\hline 1981 & 100.897 & 8,273 & 7,6 & 80,2 \\
\hline 1982 & 99.526 & 10.678 & 9,7 & 72,1 \\
\hline 1988 & 100.834 & 10.717 & 9,6 & 75,3 \\
\hline I & 99.227 & 11.450 & 10,4 & 71,2 \\
\hline II & 99.889 & 11.282 & 10,2 & 73,9 \\
\hline $\mathrm{mI}$ & 101.582 & 10.470 & 9,3 & 77,3 \\
\hline IV & 102.591 & 9.509 & 8,5 & 78,8 \\
\hline 1984 & 105.005 & 8.539 & 7,5 & 81,6 \\
\hline $\mathbf{I}$ & 103.768 & 8.882 & 7,9 & 80,5 \\
\hline$\Pi$ & 104.985 & 8.529 & 7,5 & 81,7 \\
\hline mI & 105.306 & 8.447 & 7,5 & 82,4 \\
\hline IV & 105.951 & 8.233 & 7,2 & 81,7 \\
\hline \multicolumn{5}{|l|}{1985} \\
\hline $\mathbf{I}$ & 106.732 & 8.426 & 7,3 & 81,1 \\
\hline$\Pi^{*}$ & 106.952 & 8.419 & 7,3 & 80,6 \\
\hline
\end{tabular}

* Abril y mayo.

FUENTE: Department of Commerce, Bureau of Economic Analysis. 
Roberto Bouzas / La evolución de la economía y la política económica...

Cuadro 5

INGRESOS, COSTOS SALARIALES Y PRECIOS

\begin{tabular}{llllllllllll} 
& & & & & & 1 & 9 & 8 & 4 & & 1985 \\
\cline { 5 - 8 } & 1980 & 1981 & 1982 & 1983 & Año & I & II & III & IV & I \\
\hline
\end{tabular}

Ingresos por hora (tasa anual de crecimiento, $\begin{array}{lllllllllll}\text { valores corrientes, \%) } & 9,0 & 9,1 & 6,9 & 4,6 & 3,3 & 3,3 & 3,0 & 2,8 & 2,8 & 3,7\end{array}$

Ibid. (Valores constantes) $\begin{array}{llllllllll}-4,0 & -1,0 & 0,9 & 1,5 & -0,1 & 0,4 & 0,8 & -2,7 & -0,6 & 0,3\end{array}$

Compensación por hora (valores corrientes, tasa anual de crecimiento, \%) $\begin{array}{llllllllll}10,3 & 9,6 & 8,0 & 4,9 & 4,1 & 5,4 & 3,6 & 3,6 & 3,8 & 5,6\end{array}$

Ibid. (valores constantes)

$$
\begin{array}{llllllllll}
-2,8 & -0,7 & 1,7 & 1,6 & -0,2 & 0,0 & 0,0 & 0,0 & -0,0 & 2,4
\end{array}
$$

Producto por hora (tasa anual de crecimien-
to, porcentaje)

$\begin{array}{lllll}-0,7 & 1,5 & 0,2 & 3,5 & 2,8\end{array}$

$3,1 \quad 5,3-1,1 \quad 2,3-1,5$

Costos unitarios de la mano de obra (tasa

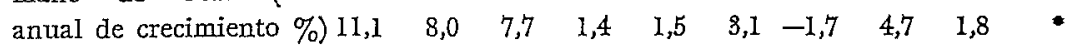
fndice de precios al consumidor (tasa anual de crecimiento, \%) $13,5 \quad 10,4 \quad 6,1 \quad 8,2 \quad 4,8 \quad 4,4 \quad 4,3 \quad 4,4 \quad 2,9 \quad 2,5$

Deflactor de precios del PNB (tasa anual de cre$\begin{array}{lllllllllll}\text { cimiento, porcentaje) } & 9,2 & 9,6 & 6,0 & 3,8 & 3,8 & 4,4 & 3,3 & 3,9 & 2,7 & 5,5\end{array}$

* No disponible.

Fuente: Department of Commerce, Bureau of Economic Analysis. 
terior, es particularmente notable la reducción en la salida de capitales privados (con la excepción de la inversión directa, estimulada por el alto valor relativo del dólar). El crecimiento de los activos de bancos norteamericanos en el exterior se redujo sustancialmente durante 1984, en buena medida como consecuencia de la precaria situación financiera externa de América Latina.

Este comportamiento del sector externo de Estados Unidos es atribuible a un conjunto de factores. En primer Iugar, el crecimiento más lento de las economías europeas y de Japón afectó adversamente la balanza comercial norteamericana. Como puede verse en la Gráfica 1 , el diferencial de crecimiento en fayor de Estados Unidos se ha ampliado constantemente desde 1983. En segundo lugar, la restricción de las importaciones de las economías en desarrollo también ha afectado las ventas de Estados Unidos al exterior. En el caso particular de América Latina y a pesar del aumento registrado en 1984, la crisis económica regional ha ocasionado que el valor de las importaciones provenientes de Estados Unidos se mantuvieran a niveles inferiores a los registrados a fines de la década del setenta.

Cuadro 6

BALANZA DE PAGOS DE ESTADOS UNIDOS, 1980/84

(Mil millones de dólares)

\begin{tabular}{lrrrrr}
\hline & 1980 & 1981 & 1989 & 1983 & 1984 \\
\cline { 2 - 6 } & $-25,5$ & $-28,0$ & $-36,5$ & $-61,1$ & $-123,3$ \\
Balanza comercial & 224,3 & 237,1 & 211,2 & 200,2 & 217,9 \\
$\quad \begin{array}{l}\text { Exportaciones } \\
\text { Importaciones }\end{array}$ & $-249,8$ & $-265,1$ & $-247,7$ & $-261,3$ & $-341,2$ \\
$\begin{array}{l}\text { Balanza en Cuenta } \\
\text { Corriente }\end{array}$ & 1,9 & 6,3 & $-9,2$ & $-41,6$ & $-101,6$ \\
$\begin{array}{l}\text { Cambio en la tenencia } \\
\text { de activos extranjeros en }\end{array}$ & & & & & \\
$\begin{array}{l}\text { Estados Unidos (-, sa- } \\
\text { lida de capital) }\end{array}$ & $-86,1$ & $-110,0$ & $-118,9$ & $-49,5$ & $-21,2$ \\
$\begin{array}{l}\text { Cambio en la tenencia } \\
\text { de activos norteameri- } \\
\text { canos por parte de } \\
\begin{array}{l}\text { extranjeros (+, entrada } \\
\text { de capital) }\end{array}\end{array}$ & & & & \\
$\begin{array}{l}\text { Discrepancia } \\
\text { Discrepancia estadistica }\end{array}$ & 25,0 & 22,3 & 32,9 & 9,3 & 30,0 \\
\hline
\end{tabular}

FUENTE: Department of Commerce, u.s-, Suruey of Current Bussines, varios números. 
Roberto Bouzas / La evolución de la economla y la política económica...

\section{Guadro 7}

COMERCIO EXTERIOR DE ESTADOS UNIDOS POR PRODUCTO

(Mil millones de dólares, CIF)

\begin{tabular}{|c|c|c|c|}
\hline & $\begin{array}{r}\text { Balinza } \\
1984\end{array}$ & $\begin{array}{c}\text { Comercial } \\
\text { Cambio } \\
\text { desde } \\
1980\end{array}$ & $\begin{array}{c}\text { Importaciones } \\
\text { de Estados Unidos } \\
\text { cambio porcentual } \\
1980-1984\end{array}$ \\
\hline Total & $-123,2$ & $-91,1$ & 35 \\
\hline Alimentos y materiàs primas & 18,4 & $-10,9$ & 13 \\
\hline Petroleo & $-53,5$ & 20,5 & -24 \\
\hline Manufacturas & $-88,7$ & $-101,2$ & 76 \\
\hline Productos quifmicos & $x 1,3$ & $-2,3$ & 61 \\
\hline Semimanufacturas & $-33,2$ & $-22,3$ & 44 \\
\hline Hierro y acero & $-10,5$ & $-5,5$ & 45 \\
\hline Textiles & $-2,2$ & $-3,4$ & 84 \\
\hline Autos, partes y motores & $-29,5$ & $-18,5$ & 83 \\
\hline Aviones civiles y partes & 5,8 & $-5,3$ & 31 \\
\hline Productos electrónicos & $-11,0$ & $-14,0$ & 162 \\
\hline $\begin{array}{l}\text { Equipo de oficina y } \\
\text { procesamiento de datos }\end{array}$ & 5,9 & $-1,7$ & 266 \\
\hline Telecomunicaciones & $-3,9$ & $-3,6$ & 142 \\
\hline $\begin{array}{l}\text { Productos electrónicos } \\
\text { de consumo personal }\end{array}$ & $-8,2$ & $-5,2$ & 128 \\
\hline Componentes & $-4,8$ & $-3,5$ & 124 \\
\hline Otros bienes de capital & 4,4 & $-19,0$ & 73 \\
\hline Productos varios & $-36,5$ & $-19,8$ & 81 \\
\hline Vestido & $-13,7$ & $-7,9$ & 109 \\
\hline Calzado & $-5,3$ & $-2,4$ & 80 \\
\hline Re-exportaciones y otros & $-5,5$ & 0,5 & \\
\hline
\end{tabular}

FUENTE: Morgan Guaranty Trust Company of New York, World Financial Markets, March/April, 1985. 


\section{Cuädro 8}

ESTADOS UNIDOS: MOVIMIIENTO DE CAPITALES, 1983/84 (Mil millones de dólares, $(\rightarrow$ ) salida de capitales)

\begin{tabular}{|c|c|c|}
\hline & 1983 & 1984 \\
\hline Balanza en cuenta corriente & $-41,6$ & $-101,6$ \\
\hline $\begin{array}{l}\text { Cambio en la tenencia de activos } \\
\text { extranjeros en Estados Unidos }\end{array}$ & $-49,5$ & $-21,2$ \\
\hline Tenencias oficiales & $-6,2$ & $-8,6$ \\
\hline Tenencias privadas & $-43,3$ & $-12,6$ \\
\hline Inversión directa & $-4,9$ & $-6,0$ \\
\hline Activos de bancos norteamericanos & $-25,4$ & $-7,3$ \\
\hline $\begin{array}{l}\text { Cambio en la tenencia de activos } \\
\text { norteamericanos por parte de extranjeros }\end{array}$ & 81,7 & 92,8 \\
\hline Tenencias oficiales & 5,3 & 3,0 \\
\hline Pasivos de bancos norteamericanos & 0,4 & 0,7 \\
\hline Tenencias privadas & 76,4 & 89,8 \\
\hline Activo de Bcos. norteamericanos & $-25,4$ & $-7,8$ \\
\hline Inversión directa & 11,3 & 21,2 \\
\hline Letras del Tesoro de Estados Unidos & 8.7 & 22,5 \\
\hline Otros bonos norteamericanos & 8,6 & 18,0 \\
\hline Pasivos de bancos norteamericanos & 49,1 & 27,6 \\
\hline Discrepancia estadística & 9,3 & 30,0 \\
\hline
\end{tabular}

FUENTE: Ibid.

Debe señalarse, sin embargo, que la influencia más significativa sobre la evolución del sector externo norteamericano durante 1984 y los años inmediatamente anteriores ha provenido del alto valor relativo del dólar. Entre 1980 y finales de 1984, el valor relativo del dólar aumentó, en términos reales, en más del 60 por ciento. Solamente entre el cuarto trimestre de 1983 y el mismo período de 1984, la divisa norteamericana aumentó su cotización vis à vis las principales monedas de otros países desarrollados en aproximadamente un 
Roberto Bouzas / La evolución de la economfa y la politica económica...

Gráfica 1

DIFERENCIAL DE CRECIMIIENTO ENTRE ESTADOS UNIDOS Y OTRAS ECONOMIAS INDUSTRIALIZADAS (\%)

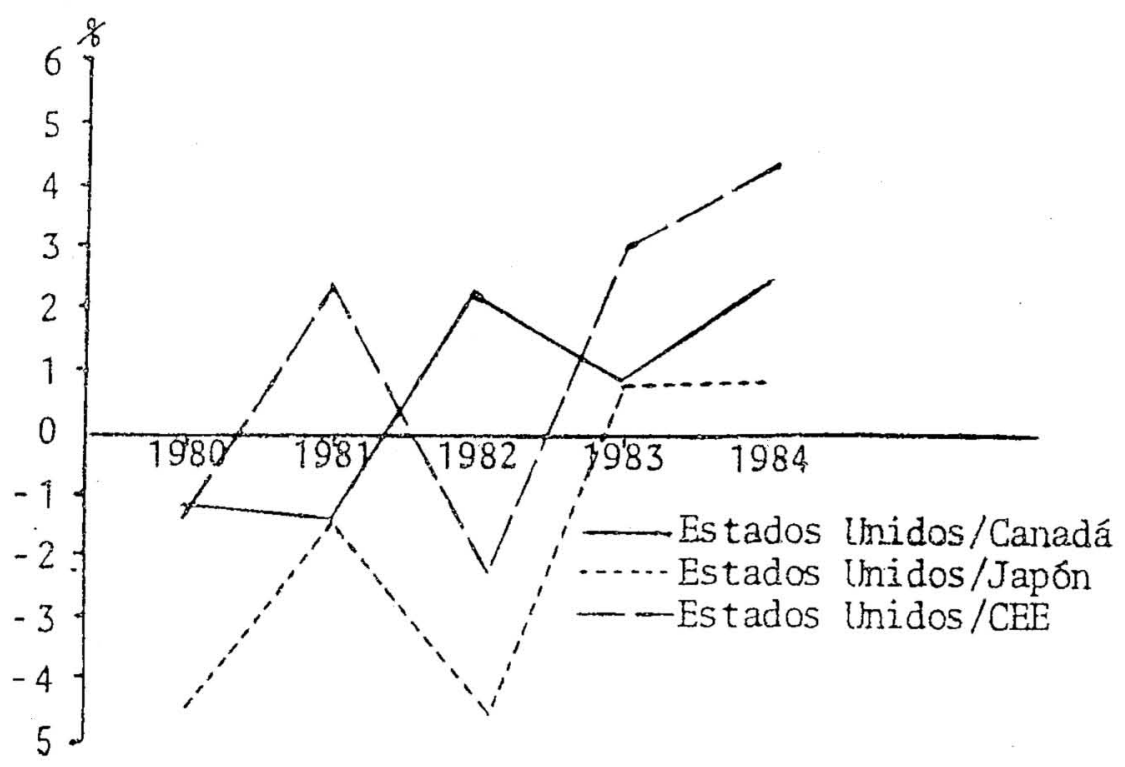

liUENTE: GLA, Op. cit.

12 por ciento (véase Gráfica 2). Este incremento en el valor relativo del dólar en un contexto de crecientes desequilibrios comerciales y en cuenta corriente, ha reafirmado la mayor influencia de los movimientos de capital en relación con los movimientos de bienes y servicios en la determinación de las tasas de cambio, al menos en el corto y mediano plazos.

Durante 1984, las tasas de interés real en Estados Unidos siguieron siendo elevadas en comparación con la experiencia histórica. Lo mismo ocurrió, aunque en proporción más modesta, con el diferencial entre el rendimiento real de los activos denominados en dólares y los denominados en otras monedas. Durante 1984, sin embargo, el 
incremento en el valor relativo del dólar tuvo lugar sin que media. ra aumento alguno en dicho diferencial. Estos comportamientos parècen confirmar la operación de un conjunto de incentivos relativamente independientes del incremento en el diferencial de rendimiento, que tendieron a reforzar la posición del dólar en los mercados monetarios internacionales. Entre éstos pueden destacarse: a) los efectos de las reducciones impositivas aprobadas por la Administración republicana durante la primera parte de su mandato sobre la rentabilidad efectiva de la nueva inversión; b) el lento crecimiento de las economfas europeas, con su secuela de escasos atractivos para la inversión; c) el exceso estructural de ahorro doméstico en el Japón; d) el lento crecimiento de las economías en desarrollo y las mediocres perspectivas de desempeño futuro, con el consiguiente estímulo para las salidas de capital; y e) las expectativas de mantenimiento de elevadas tasas de interés real en Estados Unidos como consecuencia de las escasas perspectivas de que ocurra una reducción significativa en el déficit físcal.

\section{La politica monetaria y fiscal}

Durante 1984 la politica fiscal de la Administración republicana continuó siendo considerablemente expansiva, a pesar de la ligera reducción experimentada por el déficit federal en comparación con 1983. En efecto, durante el año fiscal 1984 (que se inició el 1o. de ocubre de 1983) el déficit federal alcanzó us\$185 mil millones, comparados con us $\$ 208$ mil millones registrados durante el anterior año fiscal. Esta reducción en el desequilibrio presupuestal fue, esencialmente, resultado del comportamiento dinámico de la actividad económica y de la consiguiente operación de los estabilizadores automáticos. Según la OCDE, durante 1984 el desequilibrio estructural del presupuesto federal de Estados Unidos creció en aproximadamente 0.5 por ciento del producto nacional bruto. Esta tendencia expansiva pudo advertirse con mayor claridad en el incremento de los gastos de defensa $(8.3$ por ciento en relación con el año fiscal 1983) y de los intereses netos pagados por el sector público (casi 24 por ciento en comparación con el anterior año fiscal).

Por su parte, el presupuesto para el año fiscal 1985 presentado por la Administración al Congreso en febrero de 1983 prevela en su propuesta original un déficit aproximado de us $\$ 180 \mathrm{mil}$ millones. Con el objetivo de alcanzar tal meta, a poco de concluir el año fiscal 1984, la Administración llegó a un acuerdo con el Gongreso en torno a un conjunto de medidas de restricción en el gasto público que inclufan: ahorros en el programa de Medicare, retraso in los ajustes por aumento en el costo de vida para los pensionados y me- 
Roberto Bouzas / La evolución de la economfa y la polftica económica...

Gráfica 2

TASA DE CAMBIO NOMTNAL Y REAL DEL DOLAR

$Y$ DIFERENCIAL ESPERADO DE LA TASA DE

INTERÉS REAL, 1977/84

\section{Indice}

Marzo $1973=100$

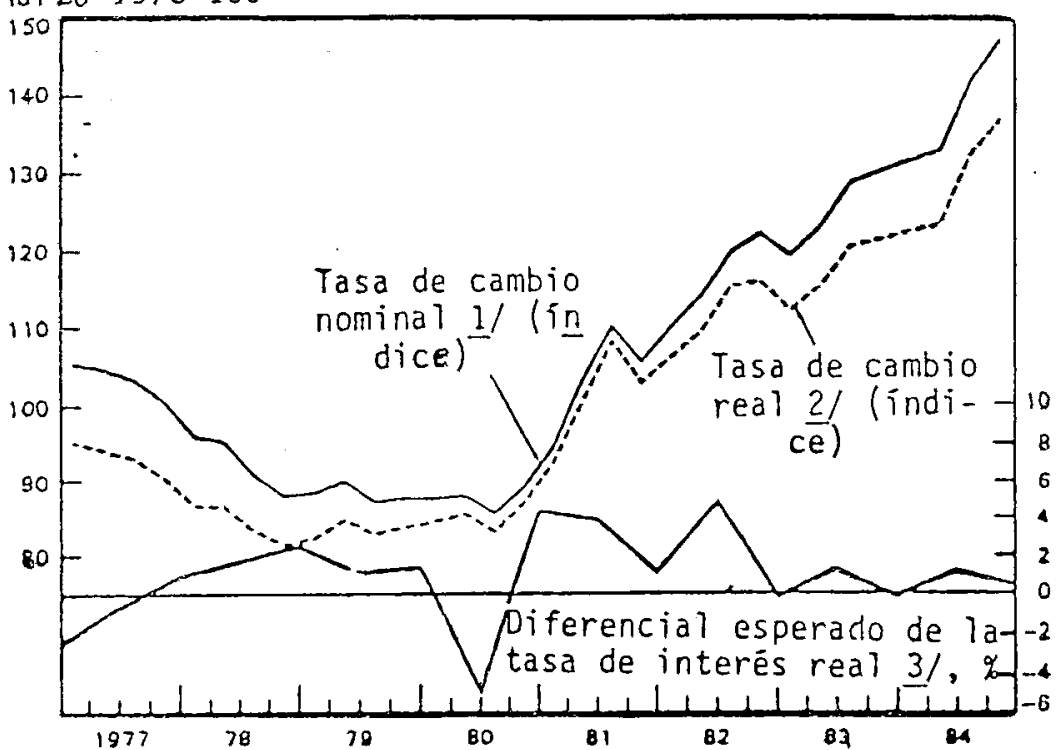

${ }^{1}$ Cotización del dólar ponderada por la participación en el comercio.

2Tasa de cambio nominal ajustada por la evolución de los precios relativos al consumidor.

"Tasa de interés (3 meses) de seis países industrializados ponderada por su participación en el comercio, ajustadsa por las prevsiiones de la ocDE con respecto a la inflación.

FUENTE: GEA, Op. Cit.

joras en el código impositivo. Sin embargo, el comportamiento de la economía y la evolución de los gastos e ingresos federales después del $1 \%$ de octubre de 1984 llevaron el déficit estimado para el año fiscal 1985 a us $\$ 222$ mil millones de dólares.

El crecimiento de los agregados monetarios siguió un curso relativamente estable en $1984 \mathrm{y}$, en el caso de $M_{1}$ y MIs, se mantuvo dentro de los límites operativos definidos por la Reserva Federal. Los objetivos de crecimiento para ambos agregados representaron una 
desaceleración de la expansión monetaria previa si se comparan con los objetivos y resultados alcanzados en 1983 (véase Guadro 9). La restriccion monetaria -particularmente durante el primer semestre de 1984- mantuvo una presión al alza en las tasas de interés nominal. La reducción de los objetivos de crecimiento monetario decidida por la Junta de la Reserva Federal en julio de 1984 multiplicó las preocupaciones de quienes advertían en la tendencia restrictiva de la política monetaria un fuerte estímulo para el crecimiento sostenido de las tasas de interés. Sin embargo, el lento crecimiento de la economía durante el segundo semestre del año y el mantenimiento de bajos registros inflacionarios, estimuló un relajamiento de la política monetaria que se reflejó en un ligero descenso de las tasas nominales de interés durante la última mitad de 1984.

Como puede apreciarse en las Gráficas 3, 4 y 5, durante 1984 las tasas de interés fueron significativamente elevadas tanto en términos nominales como reales. En la primera mitad del año, la tendencia al alza fue resultado de la ya referida dinámica expansión de la actividad económica y de las demandas de crédito, en un contexto de relativa restricción por parte de las autoridades monetarias. En el segundo semestre, sin embargo, las tasas nominales experimentan una ligera reducción, mientras que las tasas reales de interés, debido a las razones anotadas anteriormente, mantienen su tendencia ascendente.

\section{La politica económica internacional}

A lo largo de 1984 la política económica internacional de la Administración Reagan se desarrolló en un contexto bastante menos tenso y crítico que en los dos años anteriores. En efecto, la rápida recuperación económica en Estados Unidos dejó sentir su influencia expansiva sobre el resto de la economía internacional, diluyendo uno de los impactos externos más adversos de la evolución econónmica norteamericana en el período 1981-1982. Los efectos de esta mejoría fueron particularmente evidentes en el caso de un número de países en desarrollo altamente endeudados - principalmente en América Latina- que consiguieron incrementar sensiblemente sus exportaciones hacia el mercado estadounidense y alcanzar importantes superávit comerciales. La relativa mejoría en la evolución económica interna en estos países, constituyó un importante elemento de reducción de las tensiones económicas internacionales.

El mejor desempeño de la economía norteamericana e internacional durante 1984 reforzó la argumentación de la Administración republicana en el sentido de que su enfoque de dar prelación al ordenamiento económico interno y al funcionamiento de los mecanismos de mercado era esencialmente correcto. En esta perspectiva, los críticos acontecimientos del período 1981-1982, fueron interpreta- 
Roberto Bouzas / La evolución de la economía y la política económica...

Cuadro 9

OBJETIVOS DE EXPANSION MONETARIA DE LA RESERVA FEDERAL Y COMPORTAMIENTO EFECTIVO

(Tasas anuales de crecimiento, \%)

\begin{tabular}{|c|c|c|c|c|}
\hline \multirow[t]{2}{*}{ Fecha de la decisión } & \multirow[t]{2}{*}{ Periodo } & \multicolumn{3}{|c|}{$\begin{array}{l}\text { Objetivos de expansión y } \\
\text { comportamiento efectivo }\end{array}$} \\
\hline & & $\mathrm{M}_{1}$ & $\mathrm{M}_{2}$ & $\mathrm{M}_{3}$ \\
\hline Febrero 1989 & IV/1982 a IV/1983 & $4-8$ & $7-10$ & $6,5-9,5$ \\
\hline Julio 1983 & id. & $5-9$ & $7-10$ & $6,5-9,5$ \\
\hline $\begin{array}{l}\text { Comportamiento } \\
\text { efectivo }\end{array}$ & id. & 10,0 & 12,1 & 9,7 \\
\hline Julio 1983 & $\mathrm{IV} / 1983$ a IV/1984 & $4-8$ & $6,5-9,5$ & $6-9$ \\
\hline Febrero 1984 & id. & $4-8$ & $6-9$ & $6-9$ \\
\hline Julio 1984 & id. & $4-8$ & $6-9$ & $6-9$ \\
\hline $\begin{array}{l}\text { Comportamiento } \\
\text { efectivo }\end{array}$ & id. & 5,2 & 7,7 & 10,5 \\
\hline Julio 1984 & $\mathrm{IV} / 1984$ a rV/I985 & $4-7$ & $6-8,5$ & $6-9$ \\
\hline Febrero 1985 & id. & $4-7$ & $6-9$ & $6-9,5$ \\
\hline
\end{tabular}

FuenTE: Board of Governors of the Federal Reserve Board. Monetary Policy Repor to Congress, varios números.

dos como los costos inevitables de un proceso de transición hacia una trayectoria de crecimiento económico doméstico e internacional sostenido y no inflacionario.

La influencia sobre el resto de la economía internacional del rápido crecimiento en Estados Unidos y del alto valor relativo del dólar estimularon, como contrapartida, un acelerado deterioro de la 
Gráfica 8

TASAS DE INTERESS REAL Y NOMINAL DE LAS LETRAS DE LA TESOREREA DE ESTADOS UNIDOS A 90 DIAS (\% ANUAL)

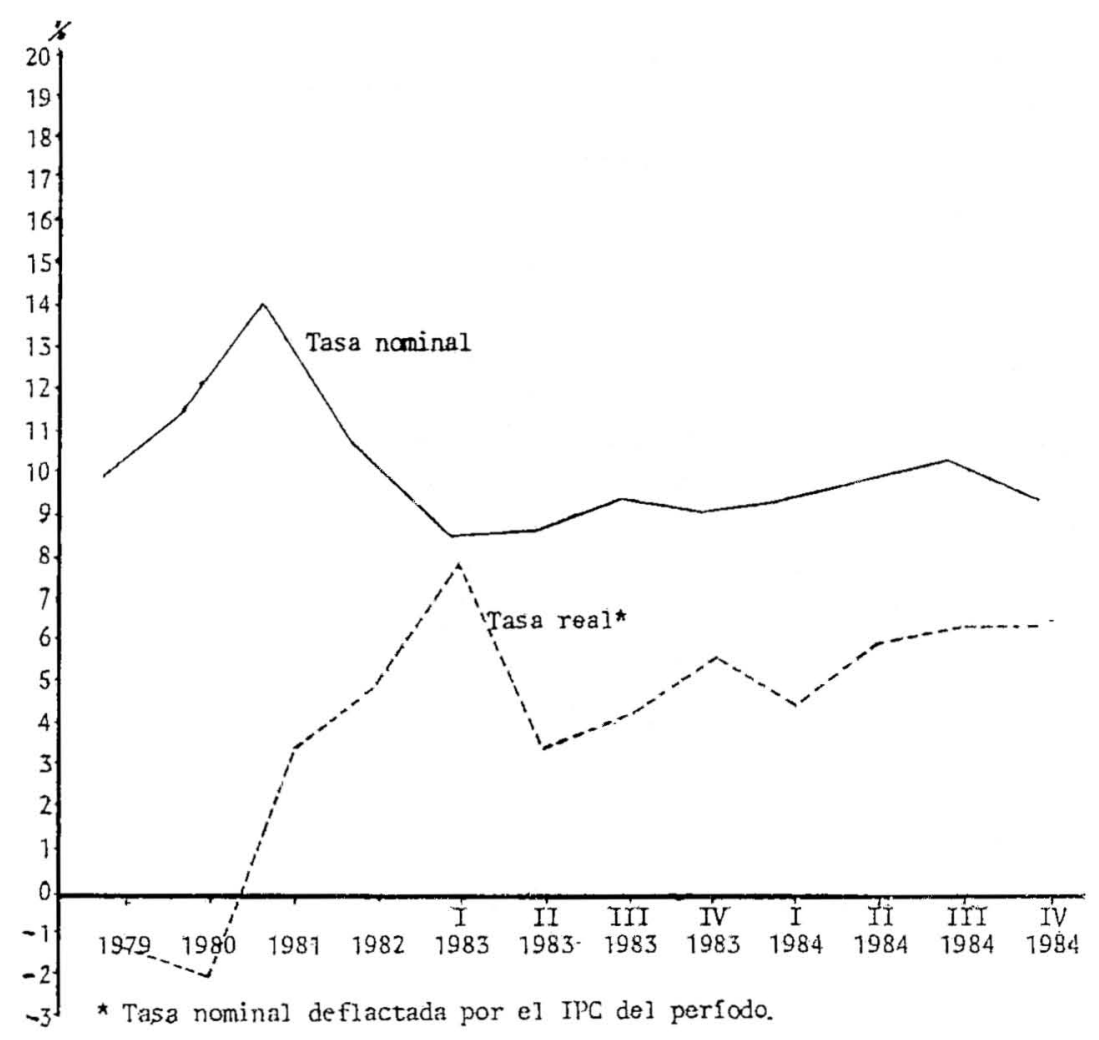

FUENTE: GEA, Op. Cit. 
Roberto Bouzas / La evolución de la economía y la polftica económica...

Gráfica 4

TASA DE INTERÉS REAL NOMINAL Y REAL DE LOS BONOS A 10 ANTOS DE LA TESORERAA DE ESTADOS UNIDOS

(\% anual)

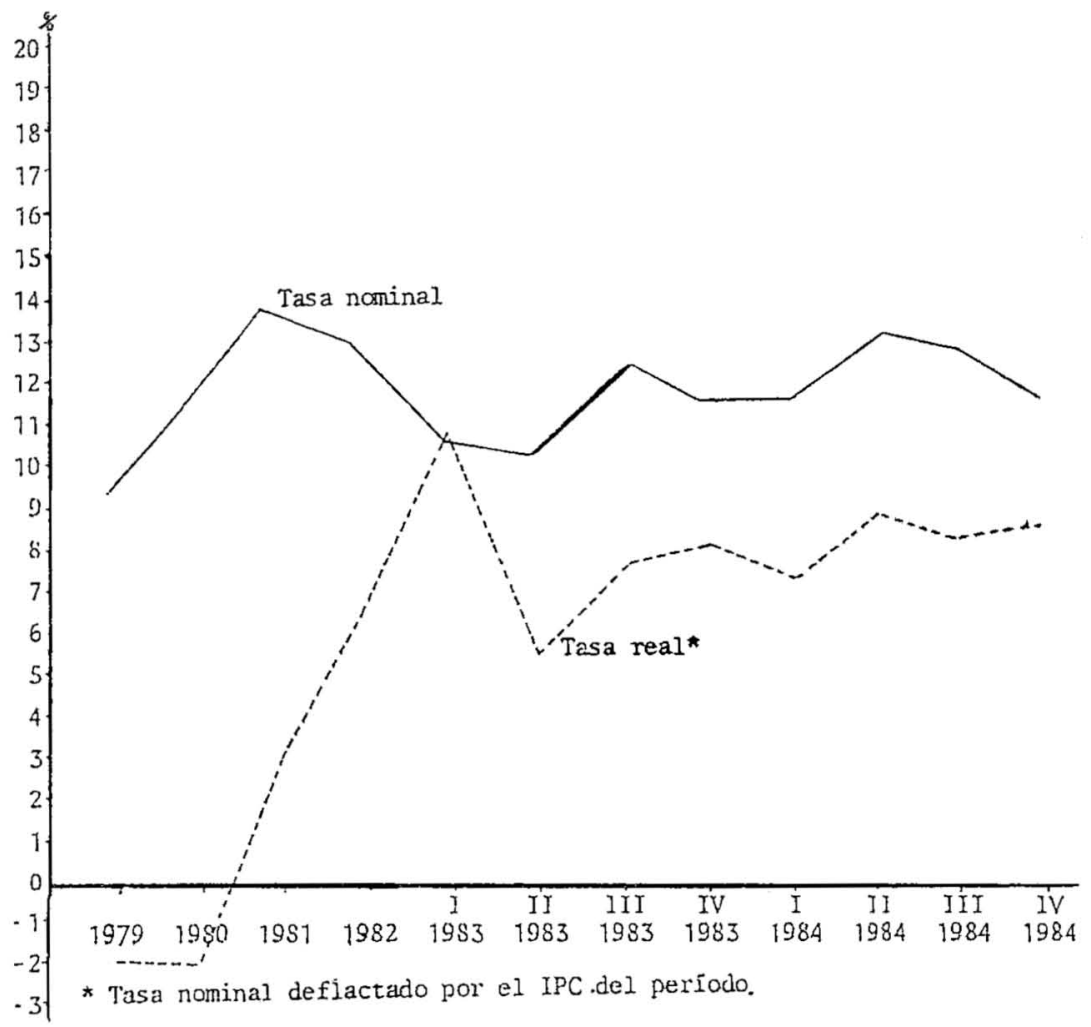

FUENTE: Ibid. 
ESTUDIOS INTERNAGIONALES

Gráfica 5

TASA PRIMA DE INTERES NOMINAL Y REAL (\% ANUAL)

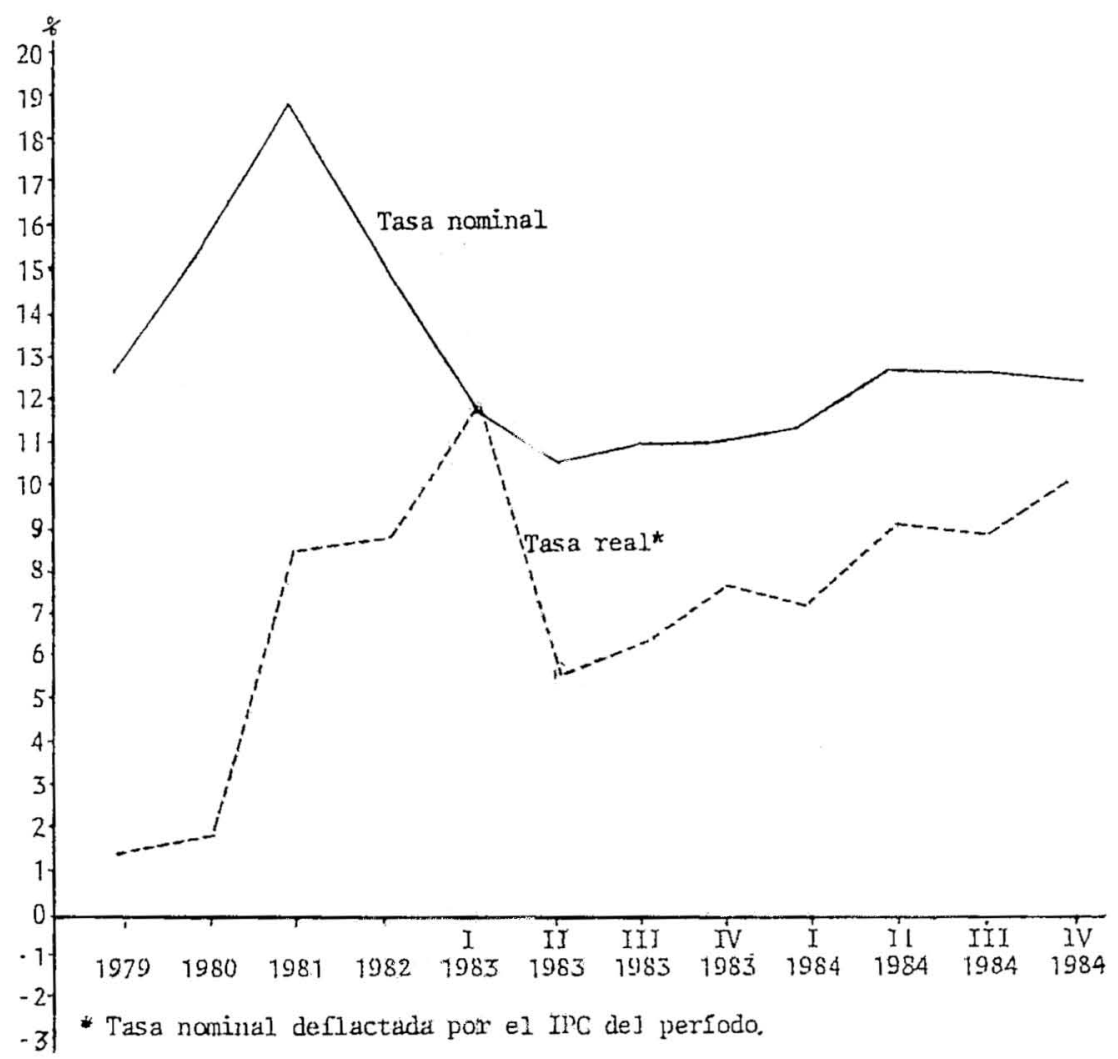

FUENTE: Ibid. 
Roberto Bouzas / ta evolución đe la economía y la polftica económica...

cuenta corriente y la cuenta de comercio norteamericanas, como ya se indicó. Estas consecuencias negativas se diluyeron, sin embargo, dentro del optimista ambiente prevaleciente.

En materia de política comercial, la decisión más significativa durante el último año fue la aprobación por parte del Congreso norteamericano de la Ley de Comercio y Aranceles de 1984. Dicha legislación renovó el Sistema Generalizado de Preferencias hasta 1993 y modificó algunos aspectos sustantivos del marco legal que regula la política comercial norteamericana, incluyendo aspectos de alta significación para las economfas en desarrollo. La nueva legislación no incorporó la mayor parte de las iniciativas altamente proteccionistas introducidas al Congreso durante 1983 y 1984, si bien autorizó la aplicación de acciones restrictivas en sectores específicos y -lo que es más importante- sancionó legalmente un conjunto de mecanismos y principios que tendrán como resultado el fortalecimiento de la posición negociadora de Estados Unidos en materia de comercio internacional.

A lo largo de 1984 se registraron, asimismo, diversos episodios de proteccionismo puntual, tal como ha sido la regla durante los últimos años. Siguiendo las recomendaciones de la Comisión de Comercio Internacional, el Ejecutivo decidió negociar acuerdos de restricción voluntaria a las exportaciones de acero con un cierto número de países, incluyendo varios de América Latina. En igual sentido, extendió por un año la vigencia del acuerdo de restricción voluntaria a la exportación de automóviles con Japón, y contrajo en un 17 por ciento la cuota azucarera, afectando negativamente a diversos países de la regín. En uno de los episodios que tuvo mayor resonancia durante el periodo, la Administración norteamericana rechazó la recomendación de la CGI para aplicar medidas temporales de protección a la industria del cobre.

En diversas oportunidades, particularmente en las reuniones cumbre de los siete principales países industrializados, en 1984 y 1985, la Administración norteamericana insistió en la adopción de un compromiso para iniciar una nueva ronda de negociaciones comerciales multilaterales, incluyendo áreas no cubiertas por el GATT, tales como el comercio de servicios, productos de alta tecnología y la inversión directa. Si bien la Administración no obtuvo los compromisos a que aspiraba en materia de calendario, consiguió transformar la cuestión de una nueva rueda de negociaciones comerciales multilaterales en un tema de primera prioridad en las relaciones con sus socios económicos industrializados y del mundo en desarrollo. En la misma dirección, durante los meses de mayo y septiembre de 1984 la Administración Reagan promovió reuniones informales para discutir aspectos de política comercial con Canadá, la Co- 
munidad Económica Europea y el Japón, y un grupo seleccionado de países en desarrollo con una activa participación en el comercio internacional, entre los cuales se contaron Brasil y México. Paralelamente, inició acuerdos y gestiones bilaterales con el doble objetivo de avanzar en programas de liberalización comercial restringidos a ciertas áreas o países (creación de un Área de Libre Comercio con Israel $y$, al mismo tiempo, crear condiciones e intereses más propicios para iniciar la citada ronda de negociaciones comerciales multilaterales.

En materia monetaria y financiera, la Administración republicana continuó haciendo efectiva su preferencia por la operación de los mecanismos de mercado y la no intervención estatal. En este sentido, aceptó pasivamente la valorización del dólar, sin manifestar demasiada preocupación por sus efectos sobre la balanza comercial norteamericana o las posibilidades de un rápido desplome de la divisa norteamericana en el futuro. Asimismo, la Administración concluyó un acuerdo con el gobierno japonés orientado a liberalizar los mercados para activos financieros denominados en yens, con el objeto de alentar una mayor internacionalización de los mercados financieros del Japón y de transformar el yen en una moneda con mayor uso internacional. Como un paso adicional para liberalizar el movimiento internacional de capitales, la Administración republicana levantó la retención impositiva que aplicaba a los intereses devengados por no-residentes sobre bonos norteamericanos y otros instrumentos financieros.

En relación con los países en desarrollo, particularmente aquellos que exhiben un elevado endeudamiento externo, la política de la Administración norteamericana continuó dando prioridad a la adopción y ejecución de programas de ajuste interno sobre la provisión de financiamiento externo. El acelerado crecimiento económico en Estados Unidos representó un alivio para la balanza comercial de algunos de Ios principales deudores, especialmente Brasil y México en America Latina. Ello contribuyó de manera importante a aliviar las tensiones sobre los mercados financieros internacionales. Los nuevos "casos críticos" que se presentaron a lo largo de 1984, particularmente en América Latina, fueron encarados con la acostumbrada combinación de auxilio de emergencia e insistencia en la aplicación de estrictos programas de ajuste interno y externo. Durante 1984, asimismo, la Administración Reagan tuvo un éxito considerable al ignorar, a un costo relativamente bajo, las propuestas e invocaciones al diálogo sobre la deuda externa realizadas por países individuales o por grupos de países en desarrollo. En este sentido, la reacción prácticamente nula por parte de la Administración Reagan ante los llamamientos y propuestas del Grupo de Gartagena constituye un ejemplo ilustrativo. 
La política de Estados Unidos en relación con los organismos financieros internacionales también ha revelado importantes signos de continuidad a lo largo de $1984^{1}$. La posición norteamericana con relación al Fondo Monetario Internacional fue claramente establecida en la Ley Pública 98-81, aprobada el 30 de noviembre de 1983, mientras que su posicion con respecto a los bancos multilaterales de desarrollo consta ampliamente en dos informes del Departamento del Tesoro, el primero de ellos publicado en febrero de 1982 (U.s. Participation in Multilateral Development Banks) y el segundo a fines de 1984 (Foreign Direct Investment and Commercial Capital Flows: the role of the Multilateral Development Banks).

En el corto plazo, el aspecto más importante de la actual posición estadounidense en relación con los organismos financieros multilaterales ha sido el apoyo a programas de estabilización y ajuste que permitan contraer la demanda agregada de las economías que se encuentren en una precaria posición externa a fin de generar un excedente que haga posible la recuperación gradual de la capacidad del país para servir la deuda. Para el mediano y largo plazos, la posición de Estados Unidos ha consistido en apoyar esquemas y programas basados en el impulso al sector privado y a la inversión extranjera dentro del marco de la libre operación de las fuerzas del mercado. Esta estrategia se ha acompañado del respaldo al menor compromiso posible de recursos propios de las instituciones y al estímulo del financiamiento por parte de terceros. En la práctica, esto se ha traducido en una mayor condicionalidad para la provisión de los recursos.

Por lo que toca al Fondo Monetario Internacional, en las últimas dos reuniones del Comité Interino -en septiembre de 1984 y abril de 1985- los representantes de Estados Unidos han expresado su oposición a cualquier propuesta de nueva asignación de Derechos Especiales de Giro (DEG) como medio de complementar la liquidez internacional disponible. Según lo ha expresado el Secretario del Tesoro, James Baker, ante la última reunión del Comité Interino del FMr en Washington, existen dos aspectos en relación con el FMI que constituyen nuevos motivos de preocupación para las autoridades norteamericanas. El primero proviene del hecho de que "el prolongado uso de los recursos del Fin está debilitando el carácter rotativo de su financiamiento y creando presiones indeseables para nuevos préstamos e incremento de las cuotas...2. El segundo se

${ }^{1} \mathrm{E} 1$ anćlisis que se realiza a continuación se basa extensivamente en el informe preparado por Drago Kisic, "Estados Unidos y los organismos financieros internacionales en 1984", mimeo.

${ }^{2}$ Discurso del Secretario del Tesoro de Estados Unidos, James A. Baker, ante el Comité Interino del FMI y el Banco Mundial. Washington D. C.; 18 de abril de 1985 . 
originá en el caso de aquellos paises en que culminan los Acuerdos de Facilidad Ampliarla y dejan, por lo mismo, de someterse necesariamente a la disciplina sistemática de un acuerdo con el FMI. En estos casos la Administración republicana ha favorecido la realización de consultas periódicas derivadas de la aplicación del Artículo IV de los Estatutos del FMI en el marco de acuerdos multianuales de refinanciación de la deuda externa con la banca privada.

Por lo que respecta al grupo del Banco Mundial, durante 1984 la Administración Reagan insistió en el fortalecimiento de la Corporación Financiera Internacional (GFI), el progresivo desplazamiento de la Agencia Internacional de Fomento (Arr), y la búsqueda de un nuevo papel para el Banco Mundial. El respaldo de la Administración republicana a la GFI quedó demostrado por el apoyo otorgado al plan quinquenal para el período $1985-1989$ y por las reiteradas manifestaciones de funcionarios norteamericanos en torno a las potencialidades de esta institución ${ }^{3}$. En cuanto a la Agencia Internacional de Fomento (AIF), durante el año pasado la Administración norteamericana rechazó el amplio consenso existente para realizar una séptima reposición de capital por un valor de us\$ 12 mil millones y exigió una reducción del 25 por ciento. Este nuevo nivel implicará una caída del 40 por ciento en la capacidad real de préstamo de la agencia.

En lo tocante al Banco Mundial, la Administración se ha negado a considerar cualquier aumento de capital, toda vez que en el año fiscal 1984 esta institución no fue capaz de colocar los 13 mil millones de dólares que tenía disponibles. En cambio, la Administración ha apoyado firmemente los esfuerzos para desarrollar un sistema imultilateral de garantía de inversiones (MIGA). El gobierno norteamericano ha respaldado el fortalecimiento de los préstamos por programa (de ajuste estructural y sectoriales), lo que daría al Banco mayor capacidad para imponer condicionalidad en aspectos relacionados con el manejo macroeconómico y le permitiría complementar la labor del finr en aspectos de mediano y largo plazos.

Por lo que toca al Banco Interamericano de Desarrollo (BID), la posición de la Administración republicana en el último año ha sido consistente con sus definiciones previas. Como consecuencia de la falta de apoyo norteamericano, el Programa de Operaciones Especiales y de Recuperación Industrial finalizarán indefectiblemente en 1985. Igualmente, la Administración Reagan ha impulsado un fuerte aumento en la condicionalidad ligada a los aspectos de ma-

séase, por ejemplo: Foreign Direct Investment and Commercial Capital Flows: The Role of Multilateral Development Banks. Documento preparado por el Departamento del Tesoro para el Congreso de Estados Unidos. Washington D. C., 1984 . 
nejo macroeconómico y ha dado su apoyo al establecimiento de la Corporación Interamericana de Inversiones (cir), que previsiblemente comenzará a funcionar en el corriente año. EI Subsecretario del Tesoro norteamericano, David Mulford, fue particularmente claro con respecto al tema de la condicionalidad en la última reunión de gobernadores del BID en marzo de 1985 en Viena. En aquella oportunidad señaló: "Creemos que el proceso de revisión de préstamos puede ser fortalecido dando una mayor participación a las oficinas que dentro del Banco tienen una mayor experiencia en asuntos sectoriales o macroeconómicos. Nosotros desearíamos una evaluación de las políticas sectoriales y macroeconómicas de cada país en todos los documentos de préstamos, aś como también cambios en la estructura organizacional del Banco a fin de mejorar la calidad cle los préstamos... Francamente, hasta que no hagamos progresos en estas dos áreas no sería productivo para nosotros discutir los parámetros financieros para las actividades futuras del Banco"s.

En el caso del BLD, durante 1984 ha sido particularmente clara la estrecha vinculación que la Administración republicana hace de su política económica internacional y de sus intereses y objetivos de seguridad. En efecto, a fines del primer trimestre de 1984 el Secretario de Estado George Shultz envió una comunicación al Presidente del BID oponiéndose a un préstamo del Banco de Nicaragua, advirtiendo que su otorgamiento haría sumamente difícil la liberación de fondos norteamericanos para el BID.

De manera más abierta y transparente, la política de ayuda bilateral de la Administración ha continuado reforzando el componente de seguridad en detrimento de la ayuda al desarrollo, promoviendo sustanciales incrementos en aquellas regiones o países que representan preocupación para la Administración norteamericana. En abril de 1985, en un ejercicio extremo de utilización de la política económica internacjonal como instrumento de promoción de los objetivos políticos y de seguridad de Estados Unidos; el Gobierno norteamericano decidió la aplicación de un embargo económico en contra de Nicaragua.

\section{LAS PERSPECTIVAS DE LA EGONOMÍA NORTEAMERIGANA EN LA SEGUNDA MITAD DE LOS AÑOS OGHENTA}

El presente capítulo incluye tres secciones principales. En la primera se evalúan las repercusiones domésticas e internacionales del déficit fiscal en la economía de Estados Unidos desde una perspec-

${ }^{4}$ Discurso del Subsecretario del Tesoro de Estados Unidos, David Mulford ante la Tercera Sesión Plenaria de la Reunión de Gobernadores del Banco Interamericano de Desarrollo, Viena, 26 de marzo de 1985. 
tiva de corto y mediano plazo. En la segunda sección se discuten algunas de las fuentes de incertidumbre y potencial inestabilidad para la economf́a estadounidense -y el conjunto de la economía internacional- en el futuro. En la última sección, se esbozan algunas de las repercusiones de estas tendencias para la región.

\section{Las consecuencias de la politica fiscal de Estados Unidos.}

Durante los últimos años, la política fiscal del gobierno estadouniclense ha tenido efectos muy significativos sobre la economía norteamericana y la economía internacional. Las medidas fiscales aplicadas por la Administración Reagan como parte del Programa de Recuperación Económica se tradujeron en un sensible aumento del déficit estructural (no cíclico) del sector público federal. La reducción impositiva aprobada en 1981 y el incremento en la tasa de crecimiento del gasto de defensa, provocaron un aumento en el déficit que fue agravado -durante el periodo 1981-1982- por las condiciones recesivas entonces predominantes en la economfa. Inversamente, la rápida recuperación que se inició en 1983 ha tenido como efecto reducir el desequilibrio efectivo como consecuencia de la operación de los estabilizadores automáticos anticíclicos. Ello no ha sido suficiente, sin embargo, para reducir el desequilibrio de las cuentas públicas a magnitudes más acordes con la experiencia histórica, como consecuencia de la señalada brecha estructural. (Véase Cuadro 14).

Cuadro 14

CAMBIOS CICLICOS Y ESTRUGTURALES EN LAS GUENTAS DEL GOBIERNO GENERAL DE ESTADOS UNIDOS (\% deI PNB)*

\begin{tabular}{|c|c|c|c|}
\hline Año & $\begin{array}{l}\text { Cambios en el } \\
\text { balance efectivo }\end{array}$ & $\begin{array}{l}\text { Estabilizadores } \\
\text { anticf́clicos }\end{array}$ & $\begin{array}{c}\text { Gambio en el } \\
\text { balance } \\
\text { estructural }\end{array}$ \\
\hline
\end{tabular}

\begin{tabular}{llll}
\hline 1980 & $-1,8$ & $-1,3$ & $-0,5$ \\
1981 & $+0,3$ & $-0,6$ & $+0,9$ \\
1982 & $-2,9$ & $-1,6$ & $-1,3$ \\
1983 & $-0,3$ & $+0,3$ & $-0,6$ \\
1984 & $+0,9$ & $+1,4$ & $-0,5$ \\
1985 & $-0,4$ & $+0,9$ & $-1,3$ \\
\hline
\end{tabular}

"Estimaciones y previsiones de la OCDE.

FUENTE: OEGD Economic Outlook, 36, December 1984, p. 30. 
Lo que otorga mayor significación a estos desequilibrios desde el punto de vista de sus efectos futuros es la perspectiva de su continuidad -suponiendo la estabilidad de las políticas actuales- por lo que resta de la década. Tal como puede apreciarse en el Cuadro 15, la Oficina de Presupuesto del Congreso anticipa el mantenimiento de una elevada participación del gasto público en el producto nacional bruto hasta fines de los ochenta, sin un correspondiente incremento en la comparativamente baja proporción de ingresos federales. Esto conducirá a elevados niveles de desequilibrio presupuestario $\mathrm{y}$, consiguientemente, en un aumento permanente del endeudamiento público. Así, mientras que a fines del año fiscal 1984 el total de deuda pública como proporción del producto nacional bruto alcanzaba el nivel más alto desde 1965 ( 36,7 por ciento), para. fines de la década dicha proporción se habrá elevado hasta cerca del 50 por ciento, una magnitud sin precedentes desde la Segunda Guerra Mundial. Este aumento en el endeudamiento público profundizará algunas de las tendencias recientes en la composición del gasto federal, tales como el incremento en la participación del pago neto de intereses en las erogaciones totales. En efecto, hacia fines de la década de los ochenta el servicio de la deuda pública federal norteamericana absorberá un 17 por ciento del gasto fiscal total, comparado con un 7,5 por ciento registrado en la segunda mitad de los setenta.

\section{Cuadro 15}

INGRESOS, GASTOS Y DEFIGIT FEDERALES EN ESTADOS UNIDOS SEGUN LA OFICINA DE PRESUPUESTO DEL GONGRESO. 1980-1990

(Años fiscales, \% del PNB)

\begin{tabular}{cccccc}
\hline Años & $\begin{array}{c}\text { Ingresos } \\
\text { Fiscales }\end{array}$ & Totales & Totales $\begin{array}{c}\text { Gastos } \\
\text { Intereses } \\
\text { Netos }\end{array}$ & $\begin{array}{c}\text { Déficit } \\
(-) \\
\text { Superáv. } \\
+\end{array}$ & $\begin{array}{c}\text { Deuda } \\
\text { Pública }\end{array}$ \\
\cline { 2 - 5 } 1980 & 20,1 & 23,0 & 2,0 & $-2,9$ & - \\
1981 & 20,8 & 23,5 & 2,4 & $-2,7$ & 27,8 \\
1982 & 20,3 & 24,5 & 2,8 & $-4,2$ & 30,5 \\
1983 & 18,6 & 25,1 & 2,8 & $-6,5$ & 35,4 \\
1984 & 18,6 & 23,8 & 3,1 & $-5,2$ & 36,7 \\
$1985^{*}$ & 19,1 & 24,6 & 3,4 & $-5,5$ & 39,6 \\
$1986^{*}$ & 19,0 & 24,1 & 3,5 & $-5,1$ & 41,8 \\
$1987^{*}$ & 19,1 & 24,3 & 3,6 & $-5,2$ & 44,0 \\
$1988^{*}$ & 19,8 & 24,5 & 3,9 & $-5,2$ & 46,0 \\
$1989^{*}$ & 19,3 & 24,5 & 3,9 & $-5,2$ & 47,9 \\
$1990^{*}$ & 19,4 & 24,7 & 4,1 & $-5,3$ & 49,7 \\
\hline
\end{tabular}

* Estimaciones.

FunNte: Congressional Budget Office, The Economic and Budget Outlook: Fiscal Years 1986/1990. UsGPo. Washington D. G., febrero 1985. 
Como puede verse en el Cuadro 16, las previsiones realizadas por la Oficina de Administración y Presupuesto son ligeramente más optimistas que las estimaciones de la Oficina de Presupuesto del Congreso, si bien ambas se mantienen dentro del mismo orden de magnitud. Las diferencias entre las estimaciones de ambos organismos pueden explicarse por los distintos supuestos utilizados en uno y otro caso por lo que respecta al ritmo de crecimiento de la economía y al nivel de las tasas de interés. (Véase Cuadro 16). Estas previsiones suponen, obviamente, la no adopción de decisiones de polftica fiscal que alteren las pautas hasta el momento prevalecientes, tanto en materia de gastos como de ingresos federales.

\section{Guadro 16}

PROYECCTONES PRESUPUESTARIAS 1985-1990

(Años fiscales, mil millones de dólares)

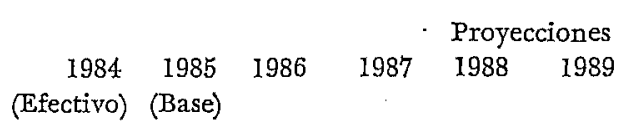

Oficina de Presupuesto

del Congreso:

$\begin{array}{lrrrrrrr}\text { - Ingresos } & 666 & 735 & 788 & 855 & 934 & 1.005 & 1.088 \\ \text { - Egresos } & 842 & 938 & 995 & 1.080 & 1.174 & 1.270 & 1.378 \\ \text {-Déficit } & -175 & -209 & -206 & -225 & -240 & -266 & -290\end{array}$

Oficina de Administración

y Presupuesto

(Servicios corrientes)*

\section{- Ingresos}

- Egresos

$\begin{array}{rrrrrr}737 & 794 & 864 & 952 & 1.030 & 1.108 \\ 960 & 1.025 & 1.109 & 1.200 & 1.263 & 1.332 \\ -224 & -230 & -246 & -248 & -233 & -224\end{array}$

Oficina de Administración

y Presupuesto (Modificaciones

propuestas 02-85):

\begin{tabular}{lrrrrrr} 
- Ingresos & 737 & 794 & 862 & 950 & 1.030 & 1.108 \\
- Egresos & 959 & 974 & 1.027 & 1.095 & 1.137 & 1.190 \\
- Déficit & -222 & -180 & -165 & -144 & -107 & -82 \\
& & & & & & \\
\hline
\end{tabular}

* Las proyecciones de servicios corrientes suponen que no hay cambio alguno en la política fiscal.

Fuente: Oficina de Presupuesto del Congreso, Op. cit., y Oficina de Administración y Presupuesto, Budget of the us Government FY 1986, uscro, Washingtor D. C. Febrero 1985. 
Roberto Bouzas / La evolución de la economia y la politica económica...

En la propuesta de presupuesto para el año fiscal 1986 presentada al Congreso por la Administración Reagan en febrero de 1985, el Presidente hizo un conjunto de recomendaciones de recortes que, de ser aprobadas por el órgano legislativo, reducirían en una magnitud importante el desequilibrio presupuestario. (Véase Cuadro 17). Los conflictos actualmente existentes en la Cámara de Representantes y en el Senado con relación a las partidas que deben ser recortadas constituyen, sin embargo, una fuente de incertidumbre sobre el resultado final del proceso legislativo. La propuesta de reforma impositiva elaborada por el Departamento del Tesoro a solicitud del Presidente Reagan, por su parte, no contempla un aumento en la partida tributaria, sino una simplificación del sistema y una reducción de las tasas de tributación.

\section{Cuadro 17}

REDUCCION PROPUESTA DE GASTOS EN EL PROYEGTO DE PRESUPUESTO PARA EL ANOO FISCAL 1986

(Años fiscales, mil millones de dólares)

\begin{tabular}{lccccc}
\hline & 1986 & 1987 & 1988 & 1989 & 1990 \\
\cline { 2 - 6 } & 1.025 & 1.109 & 1.200 & 1.263 & 1.339 \\
$\begin{array}{l}\text { Servicios corrientes } \\
\text { Cambios propuestos: }\end{array}$ & -9 & -9 & -10 & -12 & -18 \\
$\begin{array}{l}\text { - Defensa nacionaI } \\
\text { - Gasto social }\end{array}$ & -14 & -24 & -30 & -38 & -43 \\
$\quad$ no-discrecional & -21 & -86 & -45 & -50 & -55 \\
- Gasto discrecional & -4 & -3 & -3 & -3 & -2 \\
- Ingresos compartidos & -3 & -10 & -17 & -23 & -30 \\
- Servicio de la deuda & -51 & -83 & -105 & -125 & -143 \\
$\quad$ Total & 974 & 1.027 & 1.095 & 1.137 & 1.190 \\
Gastos presupuestados con & & & & & \\
$\quad$ reformas & & & & & \\
\hline
\end{tabular}

Fueste: Oficina de Administración y Presupuesto, Op. cit.

Adicionalmente, las previsiones de ingresos, gastos y déficit federales aquí referidas son válidas en el supuesto de que se verifiquen la hipótesio de comportamiento futuro de la economía. Si un proceso recesivo interrumpiera la actual recuperación o si el crecimiento efectivo fuera menor al esperado, las estimaciones del desequilibrio fiscal deberían ser correspondientemente ajustadas. Ln mismo ocurriría si hubiera modificaciones en las tasas de interés o en las 
tasas de inflación. En cualquier caso -a menos que medien cambios sustanciales en la política fiscal- aún con las hipótesis de crecimiento económico relativamente optimistas utilizadas por ambos organismos, el nivel de desequilibrio fiscal se mantendrá elevado por el resto de la década. Este hecho implica un importante cam. bio en las condiciones prevalecientes en la economía de Estados Unidos. Un cambio que, por sus características, podrá tener importantes repercusiones sobre la economía doméstica y sobre el resto de la economía internacional.

Tradicionalmente, Ia discusión relativa a los efectos de los desequilibrios en el presupuesto federal sobre lal economía transcurrió dentro de los carriles marcados por el debate entre "keynesianos" y "monetaristas". Para los primeros, en un contexto de desempleo y utilización no plena de los recursos, el déficit federal constituía un instrumento de activación de la demanda giobal y, por consiguiente, de la producción y el empleo. Para los segundos, en cambio, dicha política fiscal apenas desplazaba recursos del sector privado hacia el sector público de la economía. Si la política fiscal expansiva se acompañaba de una política monetaria flexible, el resultado sería tan sólo una tasa más elevada de inflación. La literatura sobre este tema es abundante $y$, de hecho, ocupó buena parte de las reflexiones de los economistas de las tres últimas décadas. La verificación de las distintas hipótesis alternativas fue, sin embargo, muy compleja como consecuencia de la extrema diversidad de los resultados obtenidos según las especificaciones funcionales escogidas y las variables utilizadas. Por lo mismo, este debate transcurrió durante una buena cantidad de tiempo sobre dos carriles paralelos, sin que hubiese sido posible extraer conclusiones definitivas.

\section{a) Las oonsecuencias de corto plazo}

Para los efectos analíticos, el corto plazo es normalmente definido como un período en el cual los cambios en las variables económicas que representan acervos (deuda pública, capital acumulado, fuerza de trabajo, etc.) pueden considerarse poco significativos. El efecto de corto plazo más frecuentemente referido en las discusiones sobre las consecuencias de la política fiscal sobre la economía es el que vincula los déficit y las tasas de interés. En la visión ortodoxa, un incremento en las demandas de financiam:ento del sector público aumenta el costo del crédito y, por esta vía, desplaza (crowds out) otros componentes de la demanda global sensibles a las variaciones en la tasa de interés, tales como el gasto de consumo en bienes durables y la inversión. En la versión keynesiana simple, dicho incremento en la tasa de interés puede producirse como consecuencia del aumento en la demanda de dinero que resulta del mayor nivel de actividad económica estimulado por el gasto estatal. 
Los estudios econométricos realizados en el pasado no convaliclan, sin embargo, la hipótesis de existencia de una asociación positiva entre mayores desequilibrios fiscales y tasas de interés más altas ${ }^{5}$. Las explicaciones para ello pueden ser múltiples. En primer lugar, buena parte de los resultados obtenidos pueden ser revertidos o alterados sustancialmente si se modifican las relaciones funcionales postuladas o las variables utilizadas. En segundo Iugar, dicha relación puede evolucionar de manera dispar en función de la respuesta a factores tales como cambios en la política monetaria, en la legislación tributaria, o en el grado de integración de los distintos mercados nacionales de capital. Además, la experiencia histórica no constituye necesariamente un buen ejemplo de las tendencias futuras, dado lo excepcional de la presente situación. En efecto, no existen precedentes de períodos prolongados de desequilibrios presupuestarios $\tan$ significativos en tiempos de paz en la economía de Estados Unidos.

Aún más, es posible imaginar que un incremento en el déficit público no tenderá necesariamente a desplazar otros componentes del gasto privado por la vfa de marcados aumentos en las tasas de interés si: i) dichos componentes son muy sensibles a pequeñas variaciones en las tasas de interés, o ii) los distintos mercados nacionales de capital están suficientemente integrados como para estimular el ingreso de recursos externos con movimientos menores en las tasas de interés. En este último caso, la cotización relativa de la moneda local desplazará recursos de aquellos sectores que encuentran mayores dificultades para competir con la producción importada hacia aquellos que se hallan a resguardo del deterioro en la posición competitiva (bienes y servicios no comerciables) y reemplazará producción doméstica por importaciones.

Como ya se ha señalado, la intensificación durante los últimos años del debate relativo a la existencia de una relación causal entre desecuilibrios presupuestarios y elevadas tasas de interés ha sido una consecuencia natural de la coexistencia de ambos fenómenos en el mundo real (véase Gráfica 6). Durante los primeros dos años de la Administración Reagan la heterodoxa combinación de una polftica monetaria restrictiva con una política fiscal expansiva -en un contexto de rápida desaceleración de la inflación- constituvó el principal determinante del mantenimiento de elevadas tasas de interés real. Funcionarios del Departamento del Tesoro norteamericano han rechazado la existencia de una relación causal, atribuyendo Ios elevados registros de las tasas reales de interés a la inflexibilidad de las expectativas inflacionarias de los agentes económicos. La permanencia de tasas de interés real comparativamente elevadas

${ }^{5}$ Congressional Budget Office, The Economic Outlook. A Report to the Senate and House Committee on the Budget, UsGPO, Washington D. C., febrero 1985 , p. 8314. 
en la actualidad ha servido para confirmar el carácter poco conveniente de esta explicación particularmente cuando se atiende a la experiencia de los últimos cuatro años en materia de control de la inflación y al convencimiento aparentemente generalizado sobre la solidez de la decisión de la Reserva Federal de desarrollar una política monetaria consistentemente anti-inflacionaria ${ }^{6}$.

A partir de 1980, el incremento en las tasas de interés real en el mercado norteamericano tuvo como una consecuencia paralela el aumento en el diferencial existente en favor del rendimiento de los activos denominados en dólares (véase Gráfica 2). Este incremento en dicho diferencial -en un contexto de estrecha vinculación de los mercados nacionales de capital- estimuló el ingreso de :ecursos a Estados Unidos y, consecuentemente, elevó el valor relativo del dólar. A ello contribuyó la decisión de la Administración Reagan de no intervenir en los mercados cambiarios y de dejar la determinación de la cotización del dólar al juego irrestricto de las fuerzas de mercado. El incremento en el valor relativo del dólar fue un importante elemento - si bien no el único- detrás del sensible deterioro en la balanza comercial y en la cuenta corriente de Estados Unidos. Este deterioro incrementó significativamente la presión competitiva sobre el sector productor de bienes comerciales.

Aparentemente, durante el período más reciente estos dos fenónmenos (originalmente estimulados por el mayor rendimiento relativo de los activos denominados en dólares derivado del aumento en las tasas de interés real en Estados Unidos) han sido alentados por otras fuerzas. Las expectativas de mantenimiento o incremento del valor relativo del dólar en el futuro han iugado un papel importante en el estímulo de las inversiones denominadas en la divisa estadounidense, capaz de contrarrestar un deterioro en el diferencial de tasas reales de interés. Asimismo, existe un creciente consenso en el sentido de que las reformas impositivas de 1981 habrian tenido como resultado un aumento en el rendimiento de la inversión productiva en Estados Unidos. Finalmente, algunos analistas se han referido a la acción de "efectos de empuje" (push effects) que han estimulado el ingreso de capitales a Estados Unidos y el elevado vaJor relativo del dólar?. Entre éstos se destacan: i) las pobres perspectivas para la inversión y la actividad económica en otras economfas industrializadas, principalmente europeas (el llamado "europesimismo"); ii) el "exceso estructural" de ahorro interno en Japón.

'Una explicación convincente sobre los actuales niveles de las tasas de interés real destaca el conflicto entre los desequilibrios fiscales anticipados para el futuro $y$ las expectativas de mantenimiento de una polftica monetaria poco flexible por parte de la Reserva Federal. Véase: S. Marris, "Why the dollar won't come down". Challenge, noviembre/diciembre 1984, pp. 12-20.

${ }^{7} \mathrm{C}$. Fred Bergsten, The second debt crisis: its impact on international finance and world trade, Remarks to the international forum: "The New Reaganomics and Europe", Londres, febrero 27, 1985, mimeo. 
Roberto Bouzas / La evolución de la economía y la polftica económica...

Gráfica 6

TASA DE INTERES REAL Y DEFICIT FEDERAL COMO PROPORGION DEL PNB, 1962/1984 (\%)

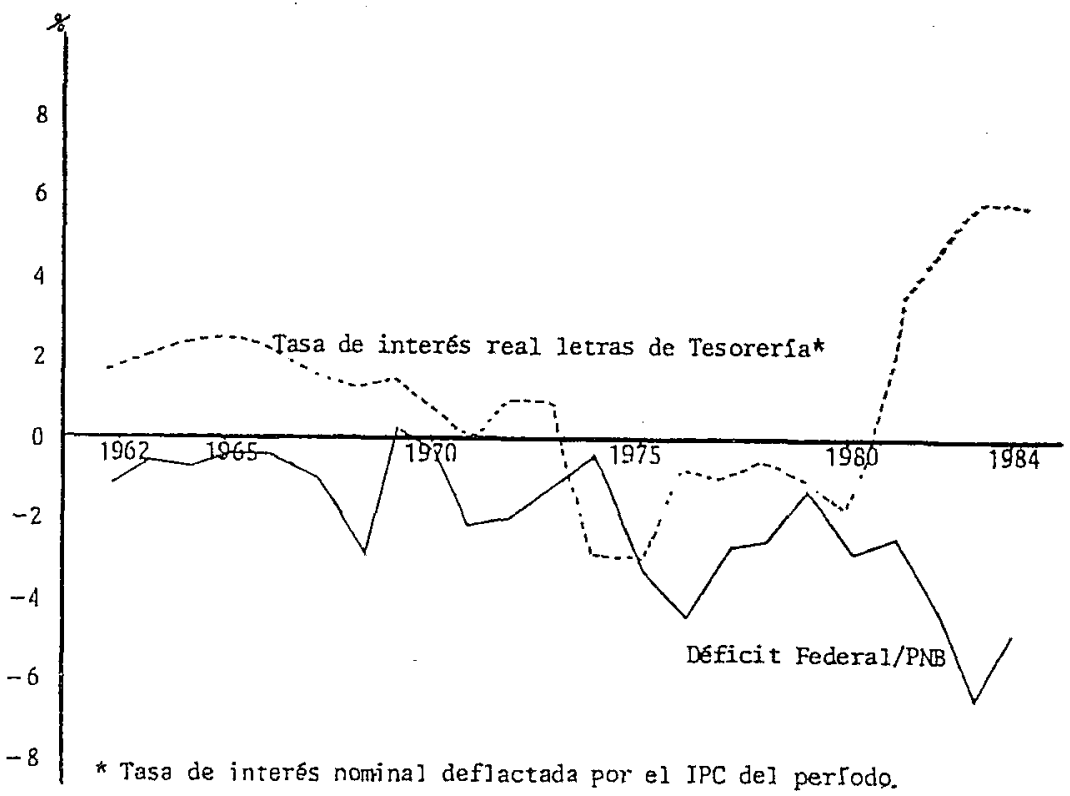

FUENTE: CLA, Up. Cit.

en comparación con los niveles de inversión doméstica; iii) la inexistencia de activos internacionales de la dimensión y atractivo que tiene el dólar; y iv) la extrema inestabilidad e incertidumbre de algunas economías en desarrollo, particularmente en América Latina, que estimula la fuga de capitales hacia alternativas más rentables y seguras. La característica dominante de los llamados "efectos de 
empuje" está en su carácter relativamente independiente de la política económica norteamericana.

En cualquier caso, la dinámica que se ha desatado ha servido para poner una seria presión sobre el sector productor de bienes comerciales en la economía norteamericana, estimulando Ia transferencia sectorial de recursos y la sustitución de producción nacional por importaciones, generando un mecanismo de crowding out alternativo al más comúnmente referido a las tasas de interés.

Otra forma de visualizar estas vinculaciones es a través del balance de ahorro e inversión. En términos puramente contables, el ahorro doméstico (público y privado) debe igualarse ex post con la inversión interna y externa. Una economía con un nivel de ahorro interno superior a la inversión doméstica canalizará la diferencia hacia el exterior, representada por una salida de capitales. Inversamente, una economía con una insuficiencia de ahorro doméstico verá reducirse su posición de inversión neta en el exterior, a través del ingreso de capitales externo. Conviene puntualizar que estas relaciones no implican vinculaciones causales, por cuanto apenas representan identidades contables que deben necesariamente materializarse ex post. Sin embargo, este esquema puede contribuir a ilustrar el efecto de elevados desequilibrios en el presupuesto federal sobre los recursos disponibles en los mercados de crédito.

Partiendo de una imaginaria situación de equilibrio, un incremento en el déficit federal (aumento en el "desahorro público") no afectará los recursos "disponibles" para la inversión doméstica si: i) se incrementa proporcionalmente el ahorro privado; ii) aumenta proporcionalmente el ahorro público a nivel estatal o local; iii) se incrementa proporcionalmente el ingreso de capitales del exterior; o iv) ocurre alguna combinación de las tres alternativas anteriores. En los últimos años, tal como ya se ha señalado, la demanda de crédito del sector federal se ha mantenido comparativamente elevada, en tanto que el ahorro interno ha experimentado apenas un ligero aumento (véase Cuadro 18). En este contexto, el boom de inversiones que ha caracterizado la recuperación 1983/1984 ha sido posible como resultado del superávit creciente de los gobiernos estatales y locales y del sosten: do ingreso de capitales externos.

En sintesis, las perspectivas de mantenimiento de elevados desequilibrios fiscales en Estados Unidos tienen diversas implicaciones para la economía norteamericana y para las del resto del mundo. En primer lugar, representa la permanencia de una presión sobre el mercado doméstico de crédito $y$, consecuentemente, sobre las tasas de interés. Esta presión podrá diluirse, en buena medida, a travẹ́s del ingreso de recursos externos, los que podrán cont:nuar mostrando un comportamiento relativamente independiente del diferencial de tasas reales de interés, como consecuencia de la operación de los llamados "efectos de empuje". Por otra parte, este dinamis- 
Cuadro 18

AHORRO E INVERSION EN ESTADOS UNIDOS, 1950-1990 (\% DEL PNB)

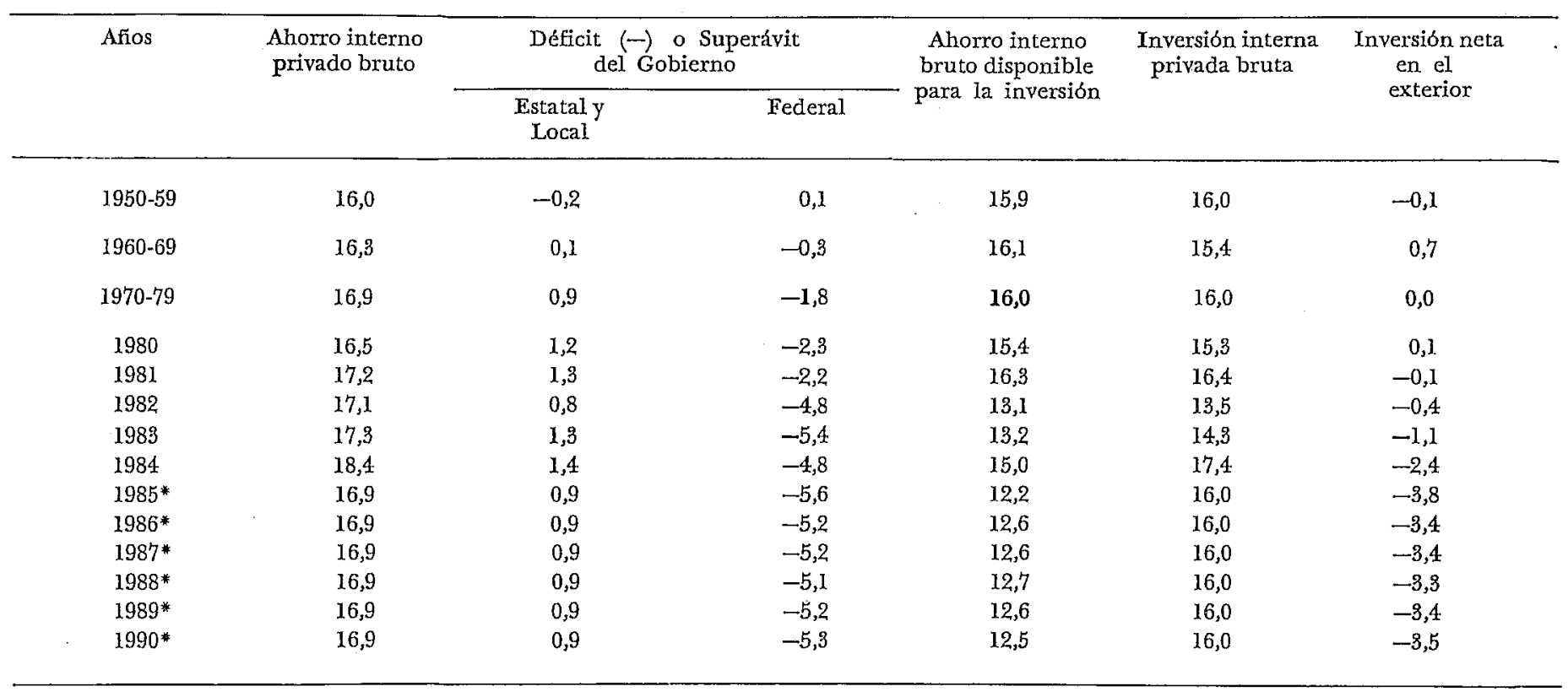

*Los valores del déficit federal son estimados. El resto corresponde al promedio 1970-1979.

Fuente: Economic Report of the President 1985, usgpo, Washington D. C., February 1985. 
mo en el ingreso de capitales al mercado norteamericano contribuirá al mantenimiento de un elevado valor relativo del dólar, con las consiguientes repercusiones sobre la competitividad de la producción norteamericana. La sucesión de agudos desequilibrios comerciales y en cuenta corriente probablemente traerá consigo un aumento de las presiones proteccionistas en Estados Unidos y acarreará una creciente incertidumbre sobre la estabilidad del esquema en su conjunto.

\section{b) Las consecuencias de largo plazo.}

La permanencia de persistentes desequilibrios presupuestarios en el futuro plantea, además, la cuestión de sus consecuencias a mediano y largo plazo. La acumulación de sucesivos períodos de desequilibrios fiscales habrá de conducir a la alteración de la composición de activos y pasivos tales como la deuda pública interna e, indirectamente, la deuda externa de Estados Unidos. Adicionalmente, la sucesión de influencias adversas sobre. el sector productor de bienes comerciables estimulará un progresivo proceso de cambio estructural con secuelas de largo plazo.

Desde el punto de vista interno, uno de los riesgos primarios de la sucesión de desequilibrios presupuestarios significativos por un período prolongado, estriba en la posibilidad de dar origen a un proceso de crecimiento explosivo del endeudamiento público. Suponiendo que el llamado déficit primario (déficit federal descontado el pago neto de intereses del endeudamiento público) sea nulo, la regla aproximada para que la deuda acumulada no crezca como proporción del producto es que la tasa de interés nominal que se aplica a su pago no sea superior al crecimiento nominal del producto. $\mathrm{Si}$ se admite que cuanto más alto sea el endeudamiento público, mayores serán las presiones al alza de la tasa de interés, cuando mayor sea el déficit fiscal más probabilidades habrá de un crecimiento explosivo del endeudamiento. Progresivamente, las posibilidades de romper este círculo vicioso quedarán limitadas a la expectativa de un superávit en el presupuesto primario que permita compensar el crecimiento explosivo de la cuenta de intereses. Esta dinámica perversa es, de hecho, bien conocida por las economías latinoamericanas, en las que el servicio de la deuda se ha transformado en una porción creciente de sus gastos públicos.

Según puede advertirse en el Cuadro 19, las estimaciones realizadas por la Oficina de Presupuesto del Congreso prevén para el resto de la década elevados niveles de desequilibrio federal y un permanente aumento -aunque a ritmos decrecientes- del endeudamiento público como proporción del producto nacional bruto. De acuerdo con estas estimaciones, el défícit primario se contraerá sistemáticamente para hacer lugar al incremento en el pago de intere- 
Roberto Bouzas / La evolución de la economía y la política económica...

Cuadro 19

DEFICIT PRIMARIO, PAGO DE INTERESES DE LA DEUDA PUBLICA $Y$ DEFIGIT TOTAL (\% DEL PNB)

\begin{tabular}{lrcc}
\hline & $\begin{array}{c}\text { Déficit } \\
\text { primario }\end{array}$ & $\begin{array}{c}\text { Pago de intereses } \\
\text { sobre la deuda }\end{array}$ & $\begin{array}{c}\text { Déficit } \\
\text { total }\end{array}$ \\
\cline { 2 - 4 } $1950-1959$ & $-0,9$ & 1,8 & 0,4 \\
$1960-1969$ & $-0,3$ & 1,1 & 0,8 \\
$1970-1974$ & 0,1 & 1,1 & 1,2 \\
$1975-1979$ & 1,8 & 1,3 & 2,6 \\
$1980-1984$ & 2,1 & 2,2 & 4,3 \\
1985 & 2,6 & 3,0 & 5,6 \\
1986 & 2,1 & 3,1 & 5,2 \\
1987 & 1,9 & 3,3 & 5,2 \\
1988 & 1,7 & 3,5 & 5,1 \\
1989 & 1,6 & 3,6 & 5,2 \\
1990 & 1,5 & 3,8 & 5,3 \\
& & & \\
\hline
\end{tabular}

FUENTE: OPC, $O p$. cit.

ses, sin afectar la participación del déficit global en el PNB. Hacia fines del decenio, casi las tres cuartas partes del déficit federal total estarán representadas por el pago de intereses de la deuda federal, en comparación con el 50 por ciento registrado en la primera parte de la presente década.

La estabilidad de la relación estimada entre déficit federal y PNB permite inferir que, al menos en términos formales, el proceso no aparece como explosivo. Sin embargo, si se considera el papel que en dicha dinámica juega la contracción del déficit pr.mario, la ocurrencia de tasas de crecimiento economico inferiores a las utilizadas para realizar la proyección de los gastos resultaría en un incremento del desequilibrio federal. La Gráfica 7 representa los principales determinantes del proceso de acumulación de deuda pública.

Aun cuando la posibilidad de un crecimiento explosivo del endeudamiento público esté fuera de lo posible en el futuro próximo, el crecimiento persistente del endeudamiento federal y sus efectos por lo que respecta a la participación de su servicio en el gasto federal global, constituye una importante fuente potencial de restricciones para la política económica. En efecto, la redúcción en la flexibilidad de la política fiscal como consecuencia de la participación creciente en los gastos totales de un componente "exógeno": como el servicio de la deuda reduce los márgenes de maniobra del gobierno federal. Adicionalmente, las inevitables presiones que el man- 


\section{Gráfica 7}

\section{DETERMINANTES DE LA ACUMULACION DE DEUDA 1955-1990}

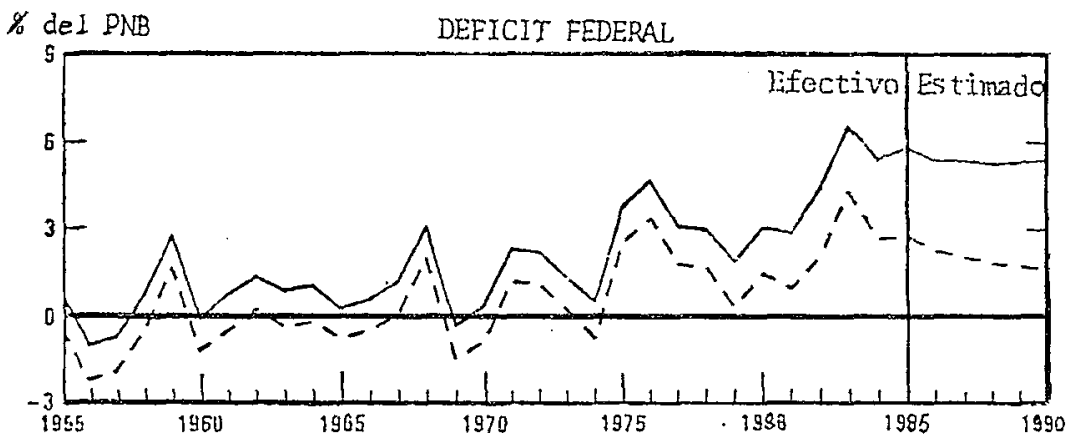

PUnLOS DIFERENCIAI, FNTRE IA TASA DE CRECIMIENTO Y DE INTERES
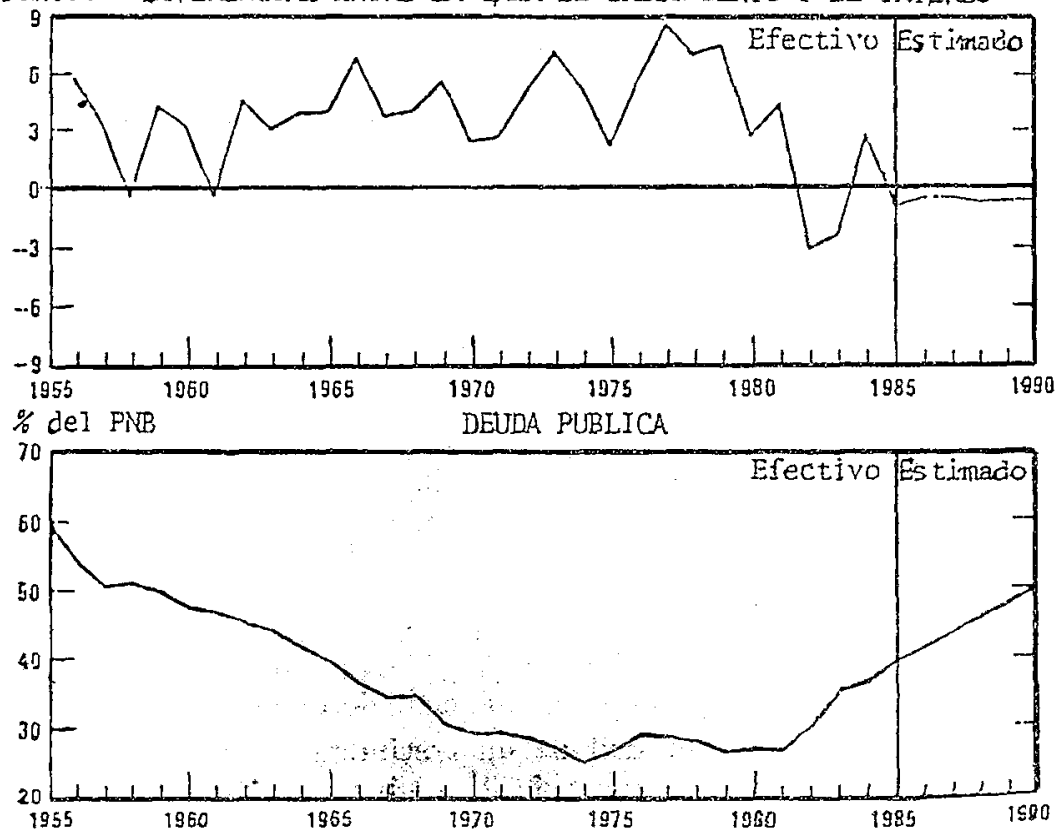

FUENTE: CBO, Op. cit.

tenimiento y acumulación de elevados desequilibrios presupuestarios ejercerán sobre la política monetaria, podrian eventualmente ocasionar una monetización del déficit y un aumento en las tasas de inflación. 
Roberto Bouzas / La evolución de la economía y la politica económica...

Para la economfa de Estados Unidos, sin embargo, la persistencia de sostenidos desequilibrios federales tiene otras consecuencias importantes a mediano y largo plazos, particularmente referidas a su posición externa. El Guadro 18 presenta un ejercicio de estima-

Gráfica 8

POSICION FINANCIERA EXTERNA DE ESTADOS UNIDOS 1970/1986 (Mil millones de dólares)

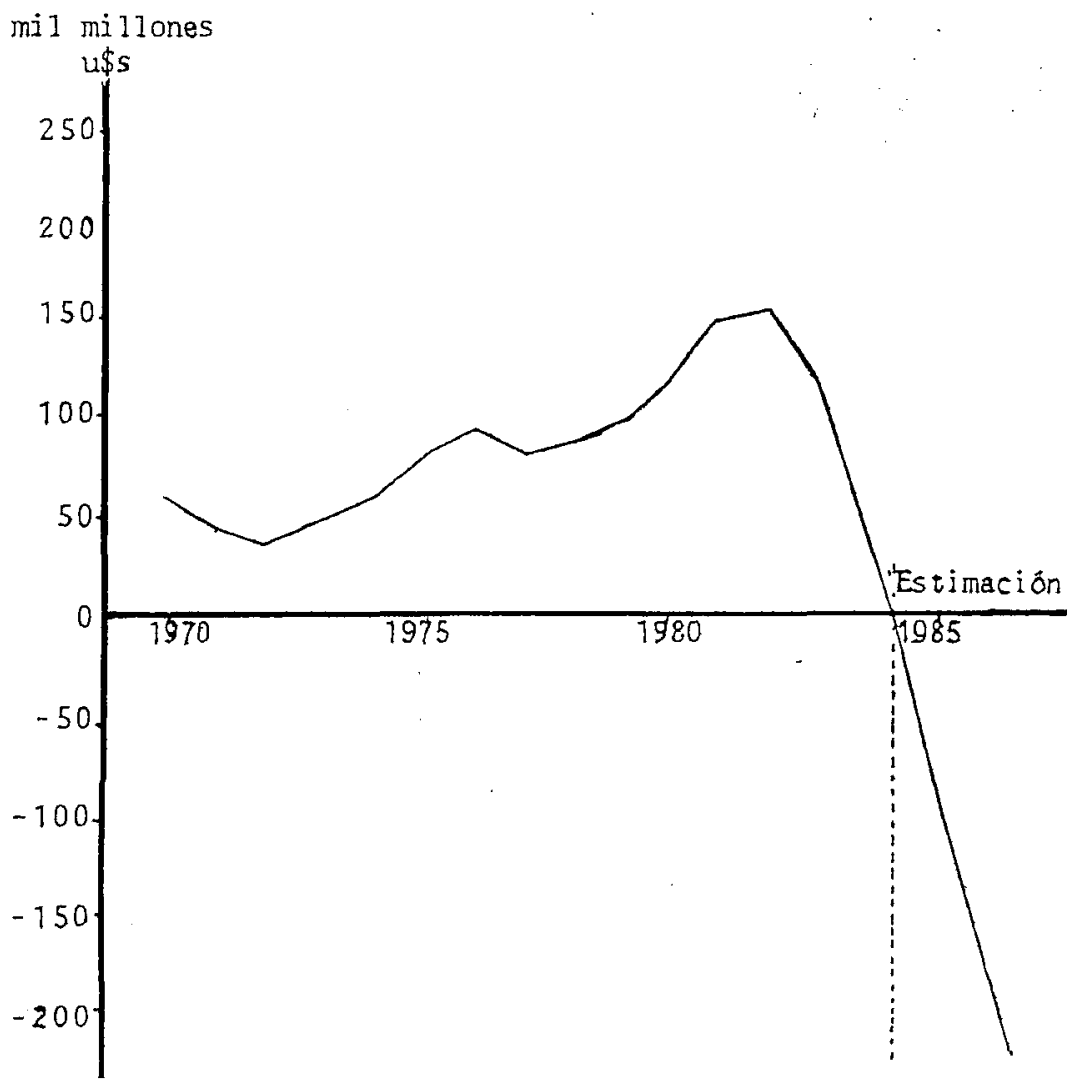

FUENTE: OPC, Op. cit. 
ción del balance de ahorro e inversión de Estados Unidos para Io que resta de la década, sobre la hipótesis de un comportamiento acorde con la experiencia histórica (registros promedio para el período 197.0-1979) parà el: ahorro interno privado bruto; el superávit de los gobiernos estatales y locales y la inversión interna privada bruta. Tomando en consideración las previsiones de la Oficina de Presupuesto del Congreso para el desequilibrio federal, el ajuste del balance de ahorro e inversión sólo podrá producirse con un ingreso sostenido de capitales externo que agudizará la posición de deudor neto a la que ingresó Estados Unidos entre fines de 1984 y principios de 1985 (véase Gráfica 8), como consecuencia del proceso de absorción de recursos externos operado durante el período 19821984. De continuar esta tendencia, para fines de 1987 la deuda externa de Estados Unidos superará la totalidad de la deuda externa de América Latina.

La acumulación de deuda externa por parte de Estados Unidos habrá de tener, entre otros, un importante efecto sobre la cuenta corriente, por cuanto su servicio se habrá de incrementar concomitantemente con el stock de endeudamiento. El Cuadro 20 presenta una estimación de la evolución del sector externo norteamericano hasta fines de la década, si no media un cambio de políticas y se mantiene la sobrevaluación del dólar. Como puede verse, a partir de 1987 la cuenta de servicios ejercerá una influencia negativa sobre las transacciones externas de Estados Unidos, al convertirse en factor importante del saldo deficitario de la cuenta corriente.

De materializarse el escenario anticipado en el Guadro 20, la sucesión de balances comerciales sistemáticamente deficitarios creará presiones al ajuste estructural de la economía norteamericana de una magnitud sin precedentes. En efecto, la ventaja competitiva de las importaciones debido al alto valor relativo del dólar constituirá una fuente significativa de desplazamiento de la producción doméstica de bienes comerciables. Ello provocaría, sin duda, una profunda alteración del perfil estructural de la economía de Estados Unidos.

\section{Algunos INTERROGANTES SOBRE LAS PERSPEGTIVAS DE LA EGONOMÍA NORTEAMERICANA Y SUS IMPLIGACIONES PARA LA ECONOMÍA INTERNACIONAL}

La mayor parte de las previsiones sobre las perspectivas de corto plazo para la economía de Estados Unidos coinciden en pronosticar una continuación del proceso de crecimiento, aunque a tasas significativamente menores a las de 1984. Tal como puede verse en el Cuadro 2I, tanto la Oficina de Administración y Presupuesto, como la Oficina de Presupuesto del Congreso, anticipan ritmos moderados de crecimiento económico para 1985, conjuntamente con bajas tasas de inflación y desempleo. Estas estimaciones son coincidentes 
Roberto Bouzas / La evolución de la economla y la política económíca...

Cuadro 20

ESCENARIO DE MEDTANO PLAZO PARA LAS CUENTAS DE COMERGIO Y CORRIENTE DE ESTADOS UNIDOS, 1984-1989

\begin{tabular}{|c|c|c|c|c|c|c|c|}
\hline _. & 1984 & 1985 & 1986 & 1987 & 1988 & 1989 & \\
\hline \multicolumn{8}{|l|}{ Sin cambio de polfticas: } \\
\hline $\begin{array}{l}\text { Balanza comercial CIF } \\
\text { (US } \$ \text { mil millones) }\end{array}$ & -123 & -155 & -165 & -163 & -167 & -180 & \\
\hline $\begin{array}{l}\text { Balanza en cuenta } \\
\text { corriente (") }\end{array}$ & -101 & -149 & -165 & -193 & -216 & -250 & \\
\hline Deuda externa neta (") & 30 & -119 & -285 & -477 & -693 & -943 & \\
\hline $\begin{array}{l}\text { PNB real (tasa anual de } \\
\text { crecimiento, } \% \text { ) }\end{array}$ & 6,9 & 3,6 & 3,3 & 2,9 & 3,2 & $3, I$ & \\
\hline Demanda doméstica (') & 8,7 & 4,0 & 3,2 & 2,9 & 3,0 & 8,0 & \\
\hline Tasa de desempleo $(\%)$ & 7,4 & 7,0 & 6,8 & 6,8 & 6,7 & 6,6 & $\therefore$ \\
\hline $\begin{array}{l}\text { Precios manufactureros } \\
\text { (tasa anual de } \\
\text { crecimiento, }(\%)\end{array}$ & 1,5 & 2,2 & 1,7 & 2,4 & 2,6 & 2,7 & \\
\hline Tasa de interés* (\%) & 10,0 & 10,6 & 9,5 & 10,6 & 10,2 & 10,1 & \\
\hline $\begin{array}{l}\text { Tipo de cambio del } \\
\text { dólar** (tasa anual de } \\
\text { crecimiento, \%) }\end{array}$ & $\begin{array}{l}\because . . \\
8,0\end{array}$ & 8,0 & 0,0 & 0,0 & $\begin{array}{l}\because \\
0,0\end{array}$ & 0,0 & \\
\hline $\begin{array}{l}\text { PNB real pafses industria- } \\
\text { les excepto Estados Uni- } \\
\text { dos (tasa anual de creci- } \\
\text { miento, \%) }\end{array}$ & . 3,5 & $\begin{array}{r}3,3 \\
.\end{array}$ & 8,5 & 3,5 & 8,0 & $\because \because$ & $\cdots$ \\
\hline
\end{tabular}

* Tasa de las letras de Tesorerfa a 6 meses.

** Tasa de cambio nominal efectiva.

Fuenre: Morgan Guaranty Trust Company of New York, World Financial Markets, March/April 1985.

con las formuladas en febrero de 1985 por la Junta de Reserva Federal, que resumen el consenso predominante entre los presidentes de los bancos que componen dicho organismo'.

Las previsiones para después de 1985 no tienen un valor compa-

Board of Governors of the Federal Reserve System, Monetary Policy Report to the Congress, Washington D. G., febrero 20 de 1985, mimeo. 
Cuadro 21

PREVISIONES Y SUPUESTOS ECONÓMICOS, 1985-1990

\begin{tabular}{|c|c|c|c|c|c|c|}
\hline & 1985 & 1986 & 1987 & 1988 & 1989 & 1990 \\
\hline \multicolumn{7}{|c|}{ Oficina de Administración y Presupuesto: } \\
\hline $\begin{array}{l}\text { - Producto nacional bruto } \\
\text { (tasa anual de crecimien- } \\
\text { miento real, cuarto trimes- } \\
\text { tre- a cuarto trimestre, \%) }\end{array}$ & 4,0 & 4,0 & 4,0 & 4,0 & 3,8 & 3,6 \\
\hline $\begin{array}{l}\text { - Defiacto: de precios del } \\
\quad \text { (tasa anual de crecimiento, \%) }\end{array}$ & 4,3 & 4,3 & $4, \mathbf{l}$ & 9,8 & 3,5 & 3,2 \\
\hline $\begin{array}{l}\text { - Tasa de desocupación } \\
\text { (cuarto trimestre, \%) }\end{array}$ & 6,9 & 6,8 & 6,5 & 6,2 & 6,0 & 5,7 \\
\hline $\begin{array}{l}\text { - Tasa de interés, letras de } \\
\text { Tesorería a } 91 \text { dfas (\%) }\end{array}$ & 8,1 & 7,9 & 7,2 & 5,9 & 5,1 & 5,0 \\
\hline \multicolumn{7}{|l|}{ Oficina de Presupuesto del Congreso: } \\
\hline $\begin{array}{l}\text { - Producto nacional bruto } \\
\text { (tasa anual de crecimiento } \\
\text { real, } \%)\end{array}$ & 3,5 & 3,2 & 3,3 & 3,4 & 3,4 & 8,4 \\
\hline $\begin{array}{l}\text { - Deflactor de precios del } \\
\text { PNB (tasa anual de creci- } \\
\text { miento, \%) }\end{array}$ & 3,6 & 4,6 & 4,4 & 4,2 & 4,2 & 4,2 \\
\hline - Tasa de desocupación (\%) & $7, \mathrm{I}$ & 6,9 & 6,7 & 6,6 & 6,4 & 6,2 \\
\hline $\begin{array}{l}\text { - Tasa de interés, letras de } \\
\text { Tesorerfa a 9i dfas }(\%)\end{array}$ & 8,3 & 8,7 & 8,2 & 8,2 & 8,2 & 8,2 \\
\hline
\end{tabular}

Fuente: Oficina de Administración y Presupuesto, Op. cit. y Oficina de Presupuesto del Congreso, Op. cit.

rable, por cuanto constituyen supuestos de comportamiento utilizados para estimar otras variables, tales como el gasto federal y el déficit público. Ellas sirven, en cualquier caso, para conocer el grado de optimismo prevaleciente entre los organismos oficiales estadounidenses por lo que respecta a la evolución de mediano plazo de la economía de Estados Unidos. Este optimismo está matizado por importantes diferencias con respecto a la evolución probable de ciertas variables $y$, en particular, de las tasas de interés. En efecto, en el Cuadro 21 puede advertirse que a partir de 1986 la divergencia en cuanto a las tasas de interés estimadas por la Oficina de Admi- 
nistración y Presupuesto y la Oficina de Presupuesto del Congreso, crece significativamente. Ello no constituye una diferencia despreciable, habida cuenta de sus efectos potenciales sobre la continuidad del proceso de recuperación, el monto del gasto federal, el valor relativo del dólar y- lo que es de interés más inmediato para las economías de América Latina- el costo del servicio de la deuda externa.

En las presentes circunstancias, las proyecciones de mediano plazo tienen un valor aún más precario como consecuencia de su dépendencia de un conjunto de factores de difícil predicción por su inestabilidad potencial. Una primera incógnita está constiturida por el monto futuro de los desequilibrios presupuestarios, dependientes tanto de decisiones especificas de política fiscal como de la evolución coyuntural de la activ:dad económica. Una segunda incógnita de importancia se refiere a la persistencia del alto valor relativo del dólar, en un contexto de desequilibrios crecientes en la balanza comercial y en cuenta corriente. A continuación se hace una discusión más pormenorizada de estos últimos aspectos.

Como ya se indicó, el incremento en el diferencial favorable al rendimiento en los activos denominados en dólares constituyó el principal móvil detrás del ingreso mavivo de capitales externos a Estados Unidos y del consiguiente proceso de aumento en el valor relativo del dólar. Más recientemente, la reducción de dicho diferencial no ha promovido un movimiento inverso debido a la influencia de otros factores, entre los que se destacan: a) el incremento en el rendimiento de la inversión productiva en Estados Unidos como consecuencia de las reformas introducidas por la Economic Recovery Tax Act (ERTA) en agosto de 1981; b) la generación de expectativas favorables sobre la cotización futura de la divisa norteamericana; y c) la operación de los "efectos de empuje" que están en buena medida fuera del ámbito de control inmediato de la política económica norteamericana.

De acuerdo con las proyecciones incluidas en el Cuadro $20-$ sobre la base del supuesto de que no se producen cambios en la política económica norteamericana y que se mantiene el valor del dólar- para fines de la década de los ochenta las inversiones en Fistados Unidos representarán alrededor del 21 por ciento del producto bruto del resto del mundo (en comparación con el 12 por ciento que representaron en 1984), mientras que la absorción de recursos externos se aproximará al 15 por ciento del ahorro bruto total del resto del mundo (comparado con 8 por ciento a fines de 1984). Aún si el dólar continuara reduciendo su valor relativo en un futuro próximo, los retrasos con que esta corrección se haría sentir en el balance comercial provocaría que los impactos de tal alteración sólo comenzarán a percibirse a fines de 1987. Por consiguiente, parte de este cambio estructural en la economía internacional ya se en- 
cuentra asegurado, aún si hubiera una corrección pronta hacia un rumbo más equilibrado 8 .

Esta acumulación masiva de endeudamiento externo por parte de Estados Unidos constituye un acontecimiento que es difícil exagerar por lo que respecta a sus efectos de corto y largo plazo y constituye un desarrollo sin precedentes en la historia económica. Un número de características de la situación prevaleciente permitiría exhibir un cierto optimismo por lo que respecta a las probabilidades de continuidad de este proceso. En primer lugar, los indicadores de "salud" financiera externa de Estados Unidos hacia fines de la década (deuda externa como proporción de las exportaciones o del PNB norteamericano) se anticipan similares a los que hoy exhiben las economías altamente endeudadas de América Latina, aunque en el caso de Estados Unidos existen un buen número de diferencias con Ios países de la región. Por un lado, constituye ciertamente una economía más sólida y estable. Por el otro, toma prestado en su propia moneda y el dólar continúa constituyendo en la actualidad la divisa de uso internacional por excelencia.

En segundo lugar, la fortaleza del dólar y el ingreso de capitales a Estados Unidos no es ya sólo el resultado de acciones contemporáneas de política económica emanadas de Washington, sino de un cuadro económico internacional cuya configuración fue significativamente influida por las políticas económicas de la Administración Reagan en la primera mitad de la década de los ochenta. En otras palabras, el éxito obtenido por la Administración Reagan en reforzar la posición relativa de la economía norteamericana vis-à-vis el resto del mundo ha ejercido un efecto significativo sobre las expectativas y sobre las posibilidades efectivas de expansión de otras economías industrializadas (particularmente de Europa Occidental) y del mundo en desarrollo.

En función de lo anterior, las limitaciones "externas" a este proceso de mantenimiento del valor relativo del dólar y de ingreso de capitales externos a Estados Unidos aparecen relativamente diluidas. Sin embargo, existen otras fuentes de inestabilidad de efecto más inmediato que podrían alterar significativamente las condiciones prevalecientes en la economía internacional en una dirección de mayor inestabilidad y conflicto. En efecto, el mantenimiento de un dólar relativamente alto continuará afectando adversamente el balance comercial y en cuenta corriente de Estados Unidos. La continuidad de este proceso habrá de poner una presión competitiva creciente sobre el sector productor de bienes comerciables, como consecuencia del deterioro de su posición vis-à-vis la producción importada. El consiguiente efecto sobre los niveles de producción y empleo estimularán la emergencia de presiones proteccionistas aún

${ }^{8} \mathrm{C}$. Fred Bergsten, Op. cit. 
mayores a las actuales, las que probablemente obtendrán la adhesión de sectores mucho más significativos de la sociedad norteamericana. La visibilidad y magnitud del desequilibrio externo y el carácter generalizado de sus efectos adversos sobre el aparato productivo norteamericano, sentarán condiciones para una coalición extremadamente poderosa y representativa favorable a una protección más efecto del mercado doméstico. Estas presiones ya han comenzado a hacerse sentir en las diversas propuestas de aplicación selectiva o generalizada de una sobretasa a las importaciones.

El incremento en las acciones proteccionistas por parte de Estados Unidos difícilmente pasaría sin respuesta por parte de sus socios comerciales del mundo desarrollado. En efecto, previsiblemente daría inicio a un proceso de represalias que amenazaría con desarticular severamente el comercio internacional. Lo que es aún más importante -ya que no requeriría de un deterioro tan significativo en la situación- la mayor protección del mercado norteamericano eliminaría la fuente más dinámica de expansión de las exportaciones de las economías en desarrollo altamente endeudadas, recreando condiciones para una nueva sucesión de crisis financieras externas. Por cierto, tales crisis tendrían lugar a continuación de una serie de años de pobre comportamiento económico y, por lo mismo, encontrarían una reducida flexibilidad política y económica para reiterar costosas fórmulas de ajuste económico interno que se habrían probado susceptibles de ser desbaratadas por acontecimientos completamente fuera del control de las autoridades económicas nacionales.

En una perspectiva de más largo plazo, la acumulación de un endeudamiento externo neto significativo por parte de Estados Unidos tendrá consecuencias aún más negativas desde el punto de vista de una interacción económica internacional colectivamente beneficiosa. En efecto, la transición hacia una situación deficitaria en Ia balanza norteamericana de servicios (como consecuencia del cambio en la posición neta de inversión de Estados Unidos) agregará su impacto negativo sobre la cuenta corriente al existente desequilibrio comercial. A menos que se admita la hipótesis de que la economf́a norteamericana podrá continuar absorbiendo indefinidamente recursos del resto del mundo, en algún momento futuro deberán generarse superávit comerciales que permitan financiar el desequilibrio en la cuenta de servicios y, de esta manera, equilibrar progresivamente la balanza en cuenta corriente. Para ello, será necesario que el resto del mundo experimente un déficit en sus transacciones comerciales con Estados Unidos. Más allá de la posibilidad de materializar tal situación en un cuadro de "europesimismo", superávit comerciales estructurales en Japón y escasez de financiamiento internacional para los países en desarrollo, la propia base productiva norteamericana que debería generar la producción exportable ha- 
bría sufrido sensiblemente, para entonces, los costos del alto valor relativo del dólar y de la aguda competencia extranjera.

Los esfuerzos de la actual Administración para iniciar negociaciones multilaterales en torno a la liberalización del comercio internacional de servicios y productos de alta tecnología adquieren su verdadera dimensión estratégica - vistos desde esta perspectiva. En efecto, la liberalización de dichos sectores probablemente abriría a la competencia internacional un conjunto de áreas en las que Estados Unidos mantiene una considerable ventaja competitiva, creando condiciones de largo plazo para una mejoría en su cuenta corriente y: definiendo un nuevo perfil para el comercio internacional. No quiere inferirse aquí que éste constituya un objetivo de política, sino apenas que existe una considerable convergencia entre las presiones competitivas que se están dejando sentir sobre la economf́a norteamericana, los esfuerzos de "racionalización" de la base productiva mediante mecanismos de mercado y ciertos componentes de la política económica internacional impulsada por la presente Administración.

En cualquier caso, existen serias dudas sobre la posibilidad que se sostenga a largo plazo un proceso de valorización del dólar con las características apuntadas. La alternativa "optimista" incluye un progresivo proceso de desvalorización lenta $y$ gradual que no introduzca tensiones en la economía internacional como consecuencia de un cambio brusco en las expectativas. Sin embargo, la evolución de la economia internacional difícilmente se da sobre bases armónicas, particularmente en períodos caracterizados por la acumulación de desequilibrios significativos y escasa coordinación de políticas. La experiencia de la década de los setenta parece demostrar que la corrección en los valores relativos de las monedas significativamente "desalineadas" tiende a darse en forma abrupta y discontinua. Ello parece reforzarse en las actuales condiciones de estrecha articulación de los mercados nacionales de capital y del papel clave jugado por las expectativas en la determinación del comportamiento económico.

Es difícil pretender anticipar los desarrollos precisos durante la segunda mitad de los ochenta. Aquí se han apuntado las mayores fuentes de inestabilidad y riesgo que encierra la actual situación económica internacional, decisivamente influencias por el estado y perspectivas de la economía norteamericana. La política económica de la Administración Reagan ha tenido éxito en reafimmar la posición hegemónica de Estados Unidos, al costo de crear importantes desequilibrios. Este éxito se ha manifestado de la manera más nítida en el significativo vuelco de las expectativas en torno a las perspectivas de largo plazo de la economía norteamericana vis-à-vis otras economfas industrializadas (particularmente Europa Occidental) y las economías en desarrollo. Un número de desequilibrios 
fundamentales, no obstante, han sido creados, permanecen presentes $\mathrm{y}$ se agudizan con el paso del t:empo.

La situación se complica aún más en la actualidad porque es altamente improbable que la acción aislada de un país pueda revertir progresivamente las tendencias aquí bosquejadas. Algunos analistas han apuntado correctamente que ni aún la Administración norteamericana tiene en sus manos instrumentos capaces de corregir unilateralmente las tendencias menos deseables de la presente situación. A modo de ejemplo, una reducción en el desequilibrio presupuestario de Estados Unidos probablemente no contribuiría sensiblemente a reducir el valor relativo del dólar, por cuanto sus efectos sobre las expectativas respecto al futuro económico de Estados Un:dos serían de carácter positivo $y$, en tal sentido, podrían estimular el ingreso de capitales a la economía norteamericana y reforzar aún más la posición relativa del dólar. La estrecha relación que existió en los primeros años de la década entre el "policy-mix" norteamericano, Ias tasas de interés real en Estados Unidos, y el valor relativo del dólar y los movimientos internacionales de capitales, en la actualidad se ha diluido bajo la operación de las expectativas desatadas durante dicho período. Es por ello, entre otras razones, que no parece posible que una acción aislada - aún proveniendo de Estados Unidos- pueda enfrentar satisfactoriamente los desequilibrios aquí bosquejados. Por otra parte, Ia mayor contribución que la actual Administración norteamericana podría hacer para mejorar las perspectivas colectivas cae fuera de sus convicciones fundamentales. La cooperación internacional $y$ la procura de acciones coletivamente implementadas parece un requisito necesario para comenzar a resolver. de manera progresiva, los desequilibrios fundamentales que predominan en la economía internacional y que amenazan con multiplicar, durante la segunda mitad de los ochenta, las turbulencias caracterfsticas del quinquenio que acaba de concluir.

\section{Las repercusiones sobre América Latina}

Los distintos interrogantes que aquí se han Ievantado con respecto a las perspectivas de la economía norteamericana en la segunda mitad de Ios ochenta, así como sus implicaciones para la economía internacional, tienen un obvio e inmediato interés para América Latina. En primer Iugar, y tal como ha quedado de manifiesto durante la primera mitad de 1985 , el dinamismo exhibido por la recuperación económica en Estados Unidos durante los últimos dos años difícilmente se mantendrá en el futuro próximo. Si el crecimiento más lento de la economía norteamericana no es compensado por una aceleración de la expansión europea y japonesa, el estrangulamiento externo por el que atraviesa la mayor parte de las economías de la región tenderá a agravarse ante la desaparición de la más activa fuente de demanda externa. 
Tal como se apuntó anteriormente, las perspectivas de reducción significativa en los desequilibrios federales - particularmente en un contexto de lento crecimiento- son relativamente escasas. La continuidad de masivos déficit federales en el futuro probablemente continuará representando una fuente de presiones sobre las tasas de interés, aun cuando estas últimas puedan beneficiarse de la menor demanda de recursos provenientes del sector privado como consecuencia de un ritmo más lento de expansión económica. No obstante, no parece razonable prever una sostenida reducción en las tasas reales de interés en el mercado norteamericano, sino más bien un comportamiento inestable, con tendencia a permanecer en los actuales niveles relativamente elevados o a incrementarse aún más si ocurriera una rápida depreciación del dólar. Estas condiciones previsibles en el mercado financiero norteamericano indudablemente habrán de afectar la posición externa de las economías de la región altamente endeudadas.

Más preocupante, en una perspectiva de mediano plazo, es la continuidad del proceso de absorción de capitales por parte de Estados Unidos, como resultado ya sea de una nueva elevación en el rendimiento de los activos denominados en dólares o de la operación de los antes mencionados "factores de empuje". La creciente absorción de capitales externos por parte de la economía norteamericana reduce la disponibilidad de recursos para las economías en desarrollo, particularmente para aquellas que presentan una situación externa más comprometida, como es el caso de varios países de la región.

Adicionalmente, si bien la continuidad del desequilibrio comercial norteamericano constituye una fuente de expansión de la demanda externa para las economías de la región, su agravamiento en el futuro probablemente alentará presiones proteccionistas de diverso tipo que obstaculizarán la colocación de las exportaciones regionales, particularmente las provenientes de los países latinoamericanos que han desplegado un mayor activismo y penetración del mercado norteamericano. Aún más, el agravamiento de las presiones proteccionistas en Estados Unidos y su previsible influencia creciente en la formulación de políticas podrá conducir a un serio deterioro del sistema de comercio internacional, agravando el ya precario contexto externo en que se desenvuelven las economías de América Latina. En cualquier caso, se reforzarán los argumentos esgrimidos por la Administración norteamericana para convocar a una nueva rueda de negociaciones comerciales multilaterales en la que se incluyan los temas de servicios e inversiones, con el consiguiente debilitamiento de la posición regional favorable a encarar de manera más progresiva y pausada cualquier negociación internacional que involucre nuevos sectores no cubiertos por el GATT.

En el mediano plazo, la transición de Estados Unidos hacia una 
posición de deudor neto del sistema internacional acabará afectando negativamente su balanza de servicios, tradicionaImente superavitaria. Ello implicará que, de no mediar un cambio de tendencia de la evolución de la cuenta comercial norteamericana, se registrará un continuo proceso de absorción de recursos externos por parte de Estados Unidos. Por el contrario, si se reduce la absorción de recursos externos como consecuencia de un mejoramiento en el balance comercial de Estados Unidos, el resto del mundo deberá estar dispuesto y en condiciones de contraer sus superávit comerciales con ese país. Si bien es cierto que dicha reducción de superávit comerciales no necesariamente afectará a todas las regiones o países, cons* tituye un desarrollo potencial adverso para la región, que difícilmente puede dejarse de lado al avaluar la magnitud y trascendencia de los desequilibrios actualmente presentes en la economía internacional.

Para América Latina, en resumen, la creciente valnerabilidad externa, que quedó nítidamente de manifiesto durante la primera mitad de la década de los ochenta, se hace más significativa como consecuencia de los profundos desequilibrios prevalecientes en la economía norteamericana e internacional. Las mejorías derivadas de ritmos más dinámicos de actividad económica en los países industrializados - particularmente Estados Unidos- y sus repercusiones sobre el sector externo de las economías de la región, no deberían hacer perder de vista el carácter de largo plazo de buena parte de las restricciones y estrangulamientos que caracterizan la situación de las economías de América Latina en la actualidad, ni las importantes fuentes de inestabilidad internacional que se mantienen a pesar de la recuperación económica de los dos últimos años. 